Replication Studies paper

\title{
Impact of financial assumptions on the cost optimality towards nearly zero energy buildings - A case study
}

\author{
Mohamed Hamdy ${ }^{\mathrm{a}, \mathrm{b}, *}$, Kai Sirén ${ }^{\mathrm{c}}$, Shady Attia ${ }^{\mathrm{d}}$ \\ a NTNU Norwegian University of Science and Technology, Department of Civil and Transport Engineering, Trondheim, Norway \\ ${ }^{\mathrm{b}}$ Department of Mechanical Power Engineering, Helwan University, P.O. Box 11718, Cairo, Egypt \\ ' Department of Energy Technology, Aalto University School of Engineering, PO Box 14400, Aalto FI-00076, Finland \\ d Sustainable Buildings Design Lab, Dept. UEE, Faculty of Applied Sciences, Univeristé de Liège, Belgium
}

\section{A R T I C L E I N F O}

\section{Article history:}

Received 19 October 2016

Received in revised form 2 June 2017

Accepted 7 August 2017

Available online 24 August 2017

\section{Keywords:}

Cost optimality

Zero energy buildings

Optimization-based parametric analysis

\begin{abstract}
A B S T R A C T
The energy efficiency challenge in Europe is mainly concerned with existing buildings and the investment scenarios to implement deep renovations. The cost-optimal approach imposed on EU-Member states by the European Energy Performance of Buildings Directive aims to identify the investment gap and challenges to transform existing buildings into nearly Zero Energy Buildings (nZEBs). The investment gap is function of several volatile financial parameters including discount rate $(r)$, developing of energy price (e), decline rate of technology price (d), as well as nZEB's incentives like feed-in-tariff (FiT) and investment grant $(i G)$. In this context, the decision making process of individuals or investment institutions is hindered by complexity and uncertainty.

In order to assist the decision making process and improve the visibility of financial energy benefits, a novel optimization-based parametric analysis scheme (OptnZEB-I) is developed. The scheme is designed to investigate a large number of economic scenarios (i.e., combinations of financial assumptions) in a short computational time while a holistic optimization approach is adopting for exploring all possible design options including energy conservation measures (ESMs); renewable energy sources (RETs) and mechanical systems (Sys).

For demonstration, the scheme is applied to analyse the impact of several financial parameters on the cost-optimal energy performance level (CO-EPL) of a single family house in Finland. In line with the EU-directive, a large number of possible design options $\left(\sim 3 \times 10^{9}\right.$ million $)$ are optimized for 4608 cases of economic scenarios. The results of the address case study show that, in average, the CO-EPL ranges from 90 to $160\left[\mathrm{kWh} / \mathrm{m}^{2}\right.$. The range has most frequent value of $145 \mathrm{kWh} / \mathrm{m}^{2}$. The CO-EPL is significantly sensitive to the $e, f$, then $i$, respectively. Less sensitivity is found to the other financial parameters.

The robustness of the optimization results are verified by solving the addressed design problem by using four different optimization algorithms (i.e., pattern search, interior-point, simulated annealing and genetic algorithms).
\end{abstract}

(c) 2017 Elsevier B.V. All rights reserved.

Abbreviations: ASHP, air source heat pump; c, calculatioin period; CO-EPL, cost-optimal energy performance level; CO-IC, cost-optimal investment cost; CO-TM, cost-

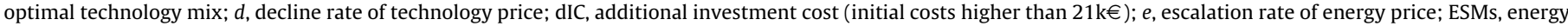

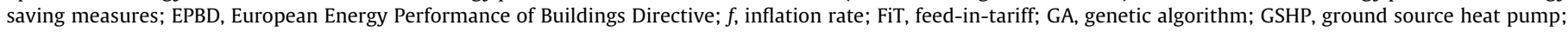

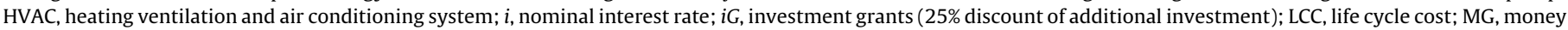

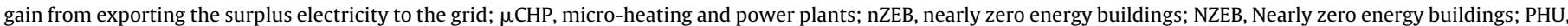

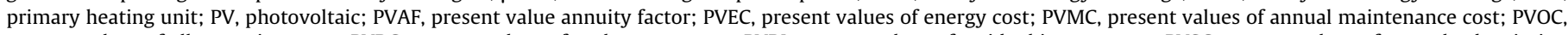

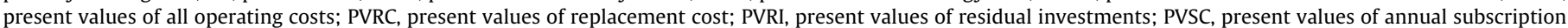
fees; PS, pattern search; RESs, renewable energy sources.

* Corresponding author at: NTNU Norwegian University of Science and Technology, Department of Civil and Transport Engineering, Trondheim, Norway.

E-mail address: Mohamed.Hamdy@ntnu.no (M. Hamdy). 


\section{Introduction}

\subsection{Background}

The long-term economic uncertainty in building's life cycle cost (LCC) analysis is mainly associated with the selection of energy price, energy price development, energy demands, performance of systems, life spans of technologies, investment costs, prevalent discount rate, as well as calculation period. This study extends the scope of nZEB relevant studies by investigating a larger number of economic assumptions and a larger number of possible design options. According to a previous literature review conducted by the authors [1], it is concluded that few economic scenarios or design options are addressed in nZEB related studies. None of the studies of Kumbaroglua and Madlener [2], Hasan et al. [3], Papadopoulos et al. [4], Georges et al. [5], Kurnitskia et al., [6], Marszal et al [7], Munjur et al. [8]. and Attia [9] investigated comprehensively the impact of the economic assumptions on the cost-optimal energy performance level (CO-EPL) towards nZEBs, in line with the EBPD-recast 2010 [10].

Here, we introduce a novel optimization-based parametric analysis scheme (OptnZEB-I) designed particularly to provide fast and detailed hourly calculations considering the current and future challenges which face applying the EBPD methodology. A holistic optimization approach is adopted to consider the significant interactions between available options of ESMs, HVACs, and RETs, simultaneously. The scheme enables the user to repeat the calculations quickly addressing different economic and/or environmental assumptions. In accordance with the Directive 2010/31/EU (EPBD recast) [10], all EU Member States are obliged to perform analysis on cost optimal levels of minimum energy performance requirements. Member States should apply and continuously use the cost-optimal methodology from now and onwards, and have to repeat it at least every 5 years. OptnZEB-I scheme is introduced to reduce the computational efforts and enhance the visualization of the building cost-optimality analysis.

\subsection{The EPBD-recast comparative framework methodology}

"The recast Energy Performance of Buildings Directive (EPBD, 2010/31/EU) [10] stands as an important milestone for building policies, requiring all European Member States to:

a) Introduce minimum energy performance requirements for buildings, building elements and technical building systems,

b) Set these requirements based on a cost-optimal methodology taking into account the lifetime costs of the building, and

c) Construct only nearly Zero-Energy Buildings (nZEB) from 2020 onwards." [11].

In order to determine cost-optimal energy performance level (energy performance level leads to the lowest cost during the estimated economic lifecycle) for EU buildings, a comparative framework methodology [12] is established to evaluate the economic and environmental feasibility of all the possible designs (all the possible combinations of compatible energy efficiency and energy supply measures). The methodology can be used also for determining cost-effective nZEB.

Fig. 1 shows the comparative methodology flowchart. After combining reference buildings with all available designs (at least 10 packages of energy-efficient measures and technical systems including RETs), the calculation splits into two: the calculation of the energy performance (using e.g., the 31 CEN standards18 [13]) and the calculation of the financial performance (using e.g., the European Standards EN 15459 [14]) of the different combinations of reference buildings and packages. The calculation of energy costs is thereby fed by the results of the energy performance calculations. A cost curve shows the assessed combinations of energy performance (x-axis) and financial performance (y-axis). It is the way that the cost optimum/cost optimal level can be derived. The relationship between current requirements and the position of the cost optimum is submitted to the commission in a reporting cycle and can be used to update requirements, if suitable. The comparison with future environmental targets could feed into a new loop, represented by the dotted line. This loop enables the effect of improved framework conditions (e.g. the introduction of economic incentives such as soft loans, feed in tariff, investment grants, etc.) to be assessed, shifting the economic optimum towards medium- or long-term targets, such as the introduction of nZEB by 2020 , and the 2050 decarbonisation goals. Therefore, it is recommended to include ambitious (as well as very ambitious) measures among selected packages in order to identify the remaining performance and financial gaps and to use accordingly these results to shape further policies and market support programs. Ambitious low-energy building standards should also be considered in order to have a timely evaluation of costs for the introduction of nZEB.

\subsection{The economic and environmental feasibility of the EPBD-recast methodology}

The economic and environmental feasibility of the EPBD-recast comparative framework methodology has been validated, before [15-19] and after [1,20-23] stipulating the directive.

In line with the European Standard EN 15459 [24], the base of the EBPD cost-optimality framework, Coninck and Verbeeck [16], Renard et al. [25], Achten et al., [26], and Georges et al., [21], investigated the cost-effectiveness of energy saving measures and/or energy supply systems for different building typologies in the context of Brussels, Flanders, and Wallonia in Belgium, respectively. They found that the global economic optimum is located at lowenergy level and not at standard or passive ones. Achten et al., [26] found that for new buildings, the legal requirements (EPB 2006: E100 and K45) of Belgium are much more inefficient than the economic optimum. Compared to the referential dwellings, the average energy saving potential for this economic optimum was $35-40 \%$ and the average economic saving over a life span of 30 years reached $15 \%$.

In line with the EPBD framework methodology, Hamdy et al., study [20] showed that the cost-optimal energy performance level of a single family house in Finland could reach $40 \%$ lower than the D3-2012 [27] standard level. The study explored the economic and environmental feasibility of a hung number of possible combinations of building envelope, HVAC, and renewables options and determined the global optimums using a transparent and time-effective optimization method. In March 2013, the Buildings Performance Institute Europe (BPIE) published a report [11] summarizes the cost-optimal energy performance level calculations for Austria, Germany, and Poland. The report showed that in Austria, the difference between actual/standard and cost-optimal energy performance level could be from $10.5 \%$ to $21.6 \%$, according to different assumptions. In Germany, the minimum energy performance requirements could be tightened by about $15 \%$ to achieve costoptimal levels and by about $25 \%$ to achieve the same global costs as the current requirements (EnEV 2009). The cost-optimal calculation for Poland revealed that there is a very big gap between current requirements (NF40 standard) and achieved results. Cost optimal energy performance level of Estonian reference detached house was significantly (39\%) lower than the current minimum requirement [28]. For selected houses built after 1990 in Portugal, Oliveira Panão [23] found that the cost optimal level should be from 22 to $33 \%$ lower than the current practice. 


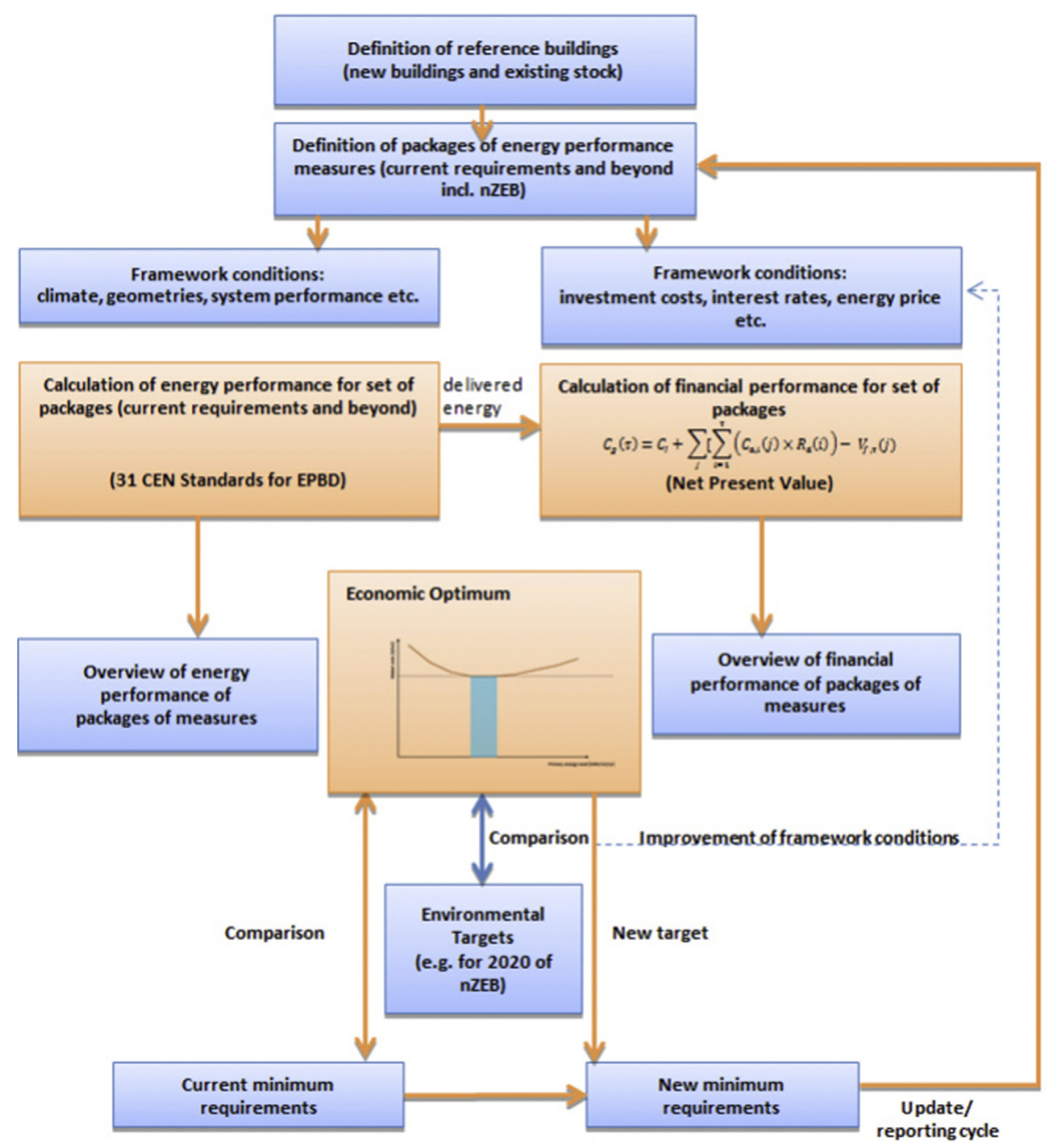

Fig. 1. Comparative cost-optimal methodology - flowchart based on [15].

Beside the European Standard (EN 15459) and the EPBD framework, it is found that it is economically beneficial to invest in environmentally friendly solutions. Papadopoulos et al., [29] showed that increasing the energy price enhance the economic feasibility of energy saving renovation measures (e.g., replacing the old window with new double-glazed ones) in urban buildings in Greece. In term of life-cycle costs (LCC), Kantola and Saari [30] found that the biogas energy, wood chip heating and ground source heating are more affordable solutions than the standard (district heating and grid electricity) for a hospital building in Finland. Bichioua and Krari [31] founded that cost-optimal building-envelope and HVAC systems selection can reduce life cycle costs by $10-25 \%$ depending on the climate and type of homes in USA.

\section{Challenges}

The actual investment gap in the deep renovation sector is not only due to up-front high investment or the long payback times but also due to the high risk of decision making. Finding a cost-optimal level for nZEBs (Fig. 2) is a tedious, uncertain and complicated task for building experts [32,33]. In the context of climate change and environmental mitigation, the building construction markets is forced to achieve significant breakthrough regarding building energy efficiency and energy neutrality [34-36]. The call for energy efficient refurbishment and investment in nZEBs

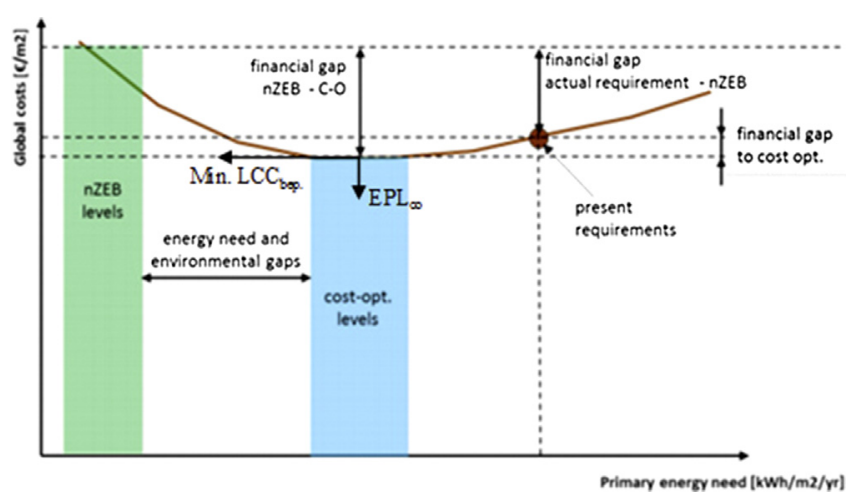

Fig. 2. Example of financial, energy and environmental gaps between current and cost-optimal requirements and nZEB levels adapted from [11].

became a status quo of the current construction sector agenda [37].The high investments generally characterized by excessively high degree of risk and invisible energy related parameters make it easy to build multiple quantitative scenarios or develop sets of comparative renovation packages. The ever-increasing number of technologies and/or technology mix are not necessarily part of an existing conventional buildings and as a result, are not always fully implemented in all commercial building performance simulation 


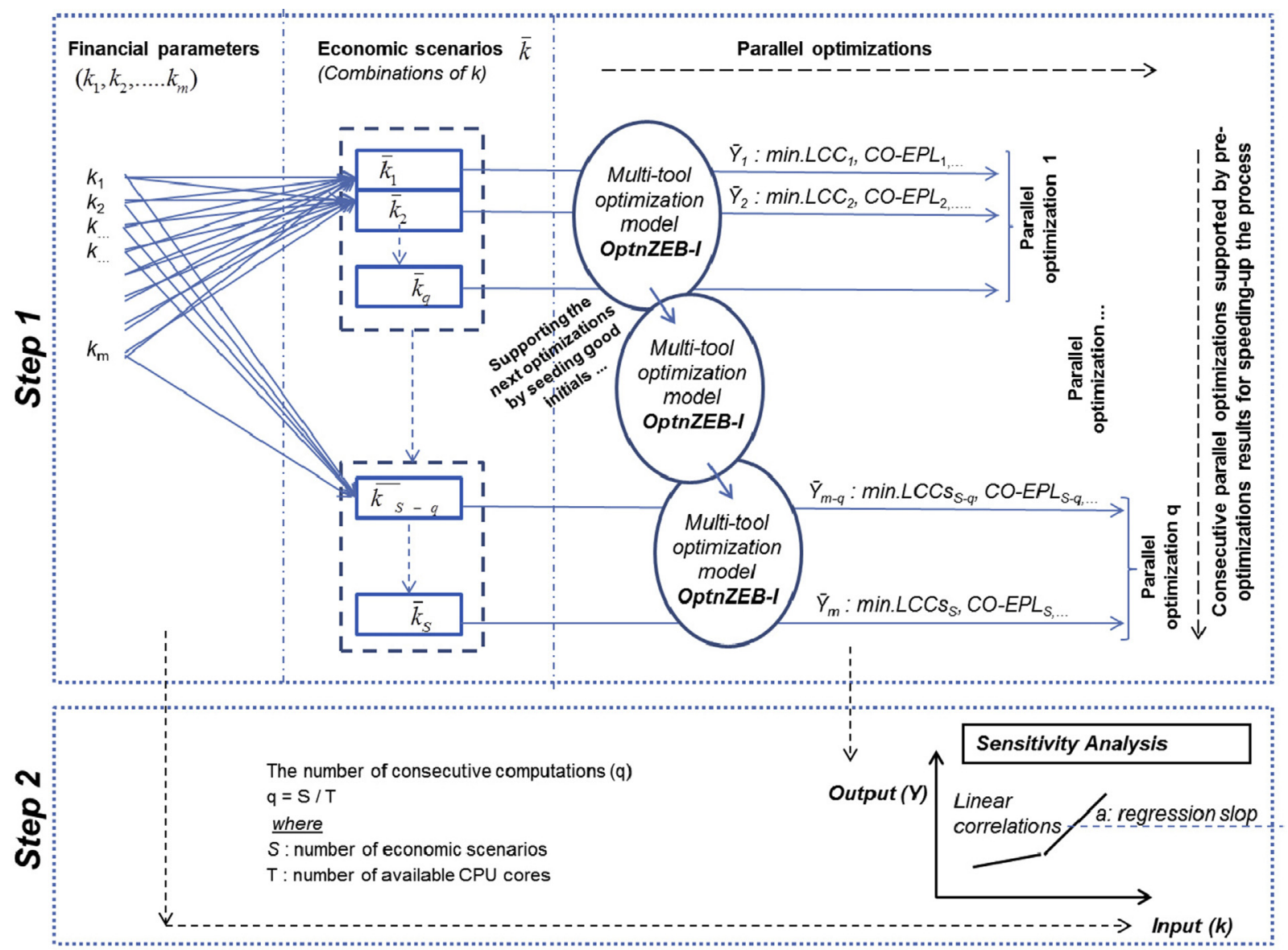

Fig. 3. The sensitivity analysis based optimization scheme.

tools [33]. When making important decisions building designers are confronted with large numbers of possible options including energy conservation measures (ESMs); renewable energy sources (RETs) and mechanical systems (Sys) that were not available 20-40 years ago [38]. Dynamic tools such as TRNSYS, and EnergyPlus could be able to capture the salient physical interactions between energy supply systems and the built environment. However, although it is common knowledge that the impact of the design decisions is greatest in earlier design stages, building performance simulation is rarely used to support early design stage tasks such as concept generation and evaluation [39-43]. Instead, multiple tools have been used to encapsulated the interactions between the different building and energy system components and obtain the necessary feedback to complete the design. Handling multiple tools is also a challenge, particularly if cost-effective environmentally-friendly solutions are desired. It is computationally expensive and technically difficult to manage building-envelope, HVACs, and RESs simultaneous optimization [79]. According to the literature, there are few tools (e.g., IDA ESBO [44]) that inform design prior to the decision making for early design stages and in the same time addresses the nearly or net zero energy objectives, combining passive and active design strategies. The available tools do not have neither exploring engines for time-efficient optimization nor visualization techniques for decision marking support [42]. More importantly, available tools are not customized to comply with the EPBD new cast for cost optimisation (EPBD, 2010/31/EU) [79].

In addition to the above simulation, optimization and visualization challenges, cost-optimal solution based on long-term life cycle cost (LCC) analysis might be sensitive to many financial and ecological assumptions. The up-front investment, payback time, volatile energy prices, energy demand, systems life span and efficiency, discount rate as well as life cycle period are sensitive financial parameters that need to be taken into account for nZEB refurbishments. Walking through these sets of financial parameters and taking decisions of the cost-optimal energy performance level ( $\mathrm{CO}$ $E P L)$ of buildings requires outsized optimization runs and huge simulation scenarios.

In this study, we aim to face the above challenges by reducing the simulation and optimization efforts by avoiding time-consuming simulations and unhelpful evaluations when possible. This is achieved by a novel simulation-based optimization scheme developed in our previous work [1]. The scheme combines and manages different tools (dynamic simulation engines, simplified models, and optimization algorithms) for applying fast but detailed cost-optimality calculations for high efficient buildings. In the concept, simplified but detailed models based post-processing pre-simulated data are used instead of running computationally expensive simulations when possible and efficient optimization algorithms is used to avoid unhelpful evaluations towards optimal solution.

\section{Methodology}

\subsection{Optimization-based parametric analysis scheme (OptnZEB-I)}

An optimization-based parametric analysis scheme (OptnZEB-I, Fig. 3) is introduced to investigate the impact of $m$ financial parameters $\left(k_{1}, k_{2}, \ldots . k_{\mathrm{m}}\right)$ on the cost-optimal energy performance level (CO-EPL, Fig. 2). Our pre-developed multi-aid optimization scheme [1] for large-scale investigation of cost-optimality and energy performance of buildings (Section 3.2) is the core of the introduced 


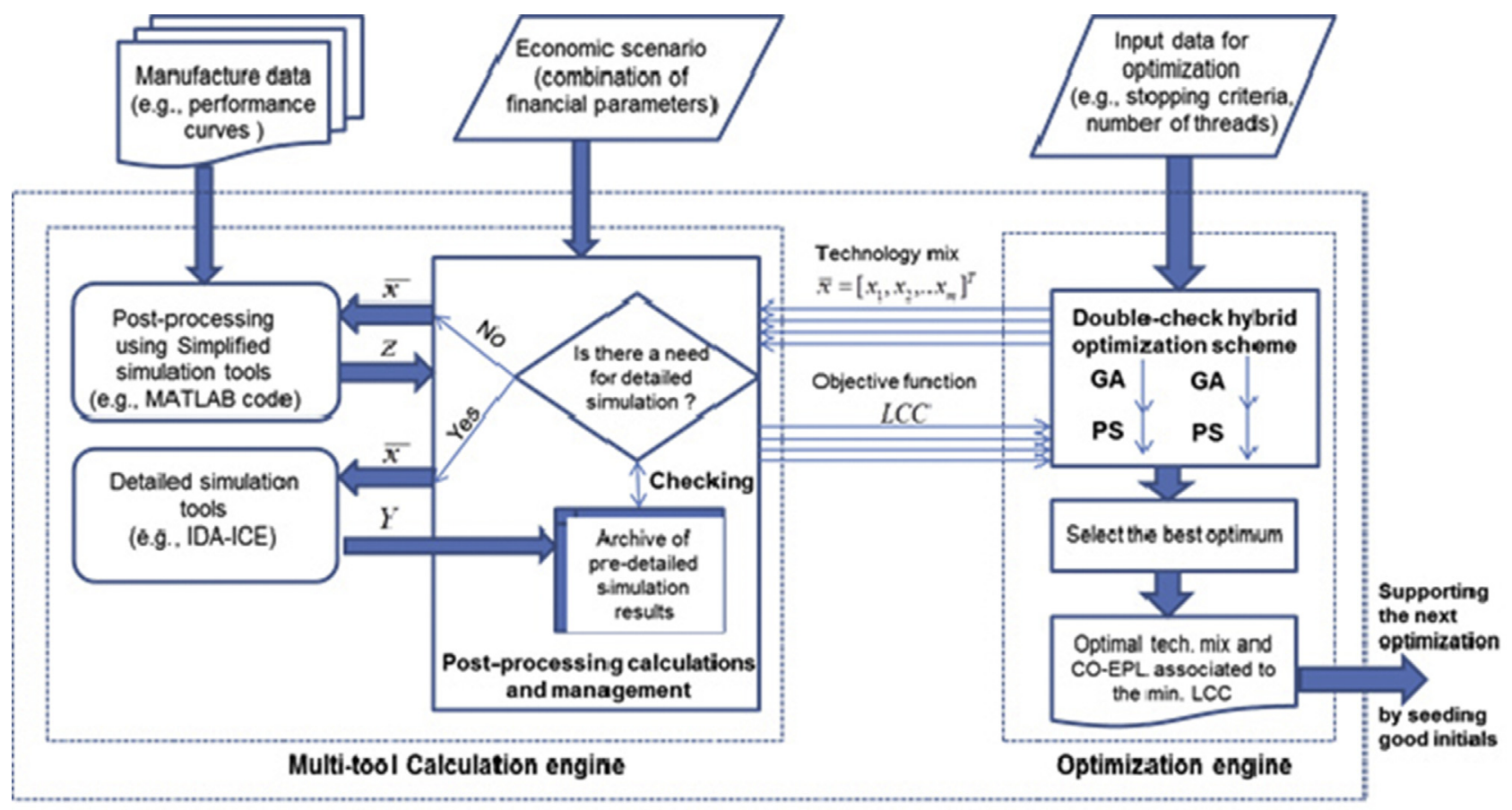

Fig. 4. OptnZEB-I: a multi-tool model for a fast and detailed simulation based optimization runs.

parametric analysis scheme (OptnZEB-I). The OptnZEB-I is designed according to the EPBD 2010/31/EU and is carried out in two steps.

In the first step, each possible combinations between the assumptions of the $m$ financial parameters is defined as an economic scenario $(\bar{k})$, Fig. 3. For each scenario, the cost-optimal energy performance level CO-EPL is determined by minimizing the life cycle cost of the building energy performance (LCC-bep) taking all initial and operating costs related to the energy performance into account. The minimum LCC-bep and its associated CO-EPL is determined by using a novel simulation-based optimization concept (OptnZEB-I, Fig. 2, a part of the scheme Fig. 3) which is able to reduce the overall time of the optimization/minimization by avoiding time-consuming simulations when possible. The calculations of the LCC-bep and the energy performance level $(E P L)$ are described in details in Section 3.3.

$S$ number of optimization runs (LCC-bep minimizations) are required to determine the $C O-E P L$ under the $S$ possible economic scenarios. This is achieved by running $q(=S / 4)$ consecutive parallel-optimization runs utilizing a quad-core powerful computer (i5-3570 CPU@3.70 HZ). The parallel computing is applied to reduce the overall time of the parametric analysis. While consecutive computations are applied when there was no capability for running anymore parallel ones. In order to speed up the consecutive optimization runs, they are seeded by good initials from the previous optimizations which have quite similar economic scenario (i.e., only one financial assumption is changed in the given scenario). So to increase the optimization efficiency of evolutionary algorithms seeding is used as a recognized technique. Therefore, we applied seeding the initial population with good or viable solutions [45], like the genetic algorithm (GA [46]) which is used here (Section 3.2). The seeding technique has been applied to many building optimization problems such as $[47-52,53,79]$. The seeded individuals are kept up to $50 \%$ of the population size to provide an appropriate amount of diversity in the initial population by letting the genetic algorithm (GA) to create the rest of initial population randomly using its creation function. One of the most determinant factors of the GA performance is the variety of population.
"Getting the right amount of diversity is a matter of start and error. If the diversity is too high or too low, the genetic algorithm might not perform well" [54].

In the second step, after determining the cost-optimal solutions for the $S$ economic scenarios, a parametric analysis is adopted to quantify systematically the sensitivity of the cost-optimal solution to the $m$ financial parameters by calculating the regression slope (a) between the input and output parameters. For example, the sensitivity of the cost-optimal investment cost (CO-IC) and the costoptimal energy performance level (CO-EPL) to the discount rate $(r)$ are expressed by the $a_{\mathrm{CO}-\mathrm{IC}}$ and $a_{\mathrm{CO}-\mathrm{COP}}$, respectively

$a_{\text {COIC }}=\frac{\Delta \text { COIC }}{\Delta r}$

$a_{C O E P L}=\frac{\triangle C O E P L}{\Delta r}$

While the other financial parameters keep unchanged.

\subsection{A simulation-based multi-aid optimization scheme (the core of OptnZEB-I)}

In order to speed up the above optimization-based analysis (Section 3.1), the LCC-bep minimizations are achieved by a simulation-based multi-aid optimization scheme developed in previous work [1]. Unlike traditional simulation-based optimization approaches, the multi-aid scheme has a feature of avoiding time-consuming simulations - when possible - while the holistic optimization approach is running for considering interaction between possibility millions design/operation variables as well as financial assumptions. The simulation-based multi-aid optimization scheme is demonstrated in [1]. Fig. 4 shows the two engines of the multi-aid scheme: multi-tool calculation engine and derivative-free optimization engine. Multiple tools (dynamic building performance modelling, archives, as well as simplified hourly models (e.g., one node buffering tank)) are employed by the calculation engine to avoid detailed simulations when possible. The optimizers can avoid detailed and tedious simulations for new variables combination with no effect on the thermal performance and 
a simplified post processing of models-based manufacturing will visualize the data. This novel concept is presented in Fig. 4 by the question "is there is a need for detailed simulation?" and illustrated in Section 4 by examples which present its time-saving feature where the OptnZEB-I is applied.

In the work, the multi-tool calculation engine is combined to an optimization engine to complete the simulation-based optimization loop. Derivative-free algorithms (Genetic Algorithm (GA) and Pattern Search (PS)) under a double-check hybrid optimization scheme, Fig. 4, are implemented. Derivative-free algorithms are known as the most suitable optimization methods for solving nonlinear building and energy system design problems $[33,37,50,56,57]$. The GA and the PR are employed under a hybrid scheme to minimize the cost function ( $\mathrm{LCC}_{\mathrm{bep}}$, Section 3.3) using a holistic optimization approach considering multivariate interactions between possible $(n)$ design/operation variables $\left(\mathrm{x}_{1}, \mathrm{x}_{2}, \ldots \mathrm{x}_{\mathrm{n}}\right)$. The GA is implemented first for a small number of generations (i.e., max 5 generations are allowed without a significant reduction 0.001 in the cost function LCC $_{\text {bep }}$ where the population size is tow times the design variables numbers $=30$ individuals) to get near an optimum point. Then the solution from the GA is used as an initial point for continuing the optimization process by the PS solver that is faster and more efficient for local minimum search. The Pattern search (PS) is halt by achieving one of the following two stopping criteria:

1) $\left|L C C_{\text {bep }}\left(\bar{x}_{i}, \bar{k}\right)-L C C_{\text {bep }}\left(\bar{x}_{i-1}, \bar{k}\right)\right|<10^{-3}$; during a minimization step

2) NE $>3000$, where NE is the maximum number of evaluations is offered to find the minimum the cost function (LCC-bep). Smaller numbers of evaluations were enough to achieve close-to-optimal solutions. However, large number (3000) is used to guarantee high quality results to detect small impacts. Thus, quality results were generated to examine the impact of financial parametric variations. Some parameters at certain circumstances have negligible impact on the results. In the double-check hybrid optimization scheme, each optimization case is run twice in parallel and the best result (the smaller min. LCC) is selected. This check was required to achieve high quality results for each optimization case. The GA is an efficient algorithm for optimization. However it could lead to different results because it's random operator [58].

\subsection{Calculations of the life cycle cost and energy performance} level

For each economic scenario, the CO-EPL was calculated based on our previous study [1]. The initial and operating cost of energy performance is included to minimize the LCC of the building energy performance ( $L C C$-bep).The construction and demolition costs are behind the scope of the LCC-bep calculations. In line with the Directive 2010/31/EU's comparative framework methodology described by [59], we omitted the cost of building components not related to energy performance.

The life cycle cost of $L C C_{\text {bep }}$ represent as a function of installed technology mix $(\bar{x})$ for building energy performance of a given financial scenario $(\bar{k})$

$$
\min \left\{\operatorname{LCC}_{\text {bep }}(\bar{x}, \bar{k})\right\} \bar{x}=\left[x_{1}, x_{2}, \ldots . x_{n}\right] \text { and } \bar{k}=\left[k_{1}, k_{2}, \ldots . k_{n}\right]
$$

where

$\mathrm{x}_{1}, \mathrm{x}_{2}, \ldots \mathrm{x}_{\mathrm{n}}: n$ number of design and/or operation variables of installed technology mix $(\bar{x})$,

$\mathrm{k}_{1}, \mathrm{k}_{2}, \ldots \mathrm{k}_{\mathrm{m}}: m$ number of financial parameters for $S$ number of financial/economic scenario $(\bar{k})$.
From the household perspective, the $L C C$-bep is defined as a sum of investment costs (ICS) as well as present values of replacement and operating costs (PVRCs and PVOCS), subtracted by the investment grant $(i G)$ provided by the government or technology supplier as well as by the present value of residual investments (PVRI) and the present value of money gain (PVMG) from exporting electricity to the grid. All the costs are divided by the net heating area of the building $\left(\mathrm{A}_{\mathrm{bldg}}\right)$ to calculate the specific $L C C_{\mathrm{bep}}$

$L C C_{b e p}=\frac{I C+P V R C+P V O C-i G-P V R I-P V M G}{A_{b l d g}}$

The investment cost $(I C)$ is the summation of all initial costs -including taxes- related to installing building and/or system technologies such as energy system, energy efficiency measures (EEMs), and/or renewable energy source (RESs)

IC $=\sum_{i}^{I} I C_{i}$

where, I denotes the number of installed technologies.

The present values of replacement cost $(P V R C)$ is the summation of costs required for replacing the installed technologies when their life expectancy are spent. To calculate the $P V R C$, the costs at the time of replacement $(R C)$ is discounted considering the discount rate $(r)$ and the replacement time $(R T)$

$P V R C=\sum_{i}^{R I} \frac{1}{(1+r)^{R T_{\mathrm{i}}}} \times R C_{i}$

where, $R I$ denotes the number of replaced items.

The discount rate $(r)$ considers the influence of the nominal interest rate $(i)$ and prevailing inflation rate $(f)$ on the present value $(P V)$ of the money

$r=\frac{i-f}{1+f}$

The deduction in technology price is considered to calculate the replacement cost $(R C)$ at the time of replacement $(R T)$ using the decline rate $(d)$

$R C=(1-d)^{R T} \times I C$

where, IC denotes the initial price of the technology.

The operating costs include all annual costs such as maintenance cost $(M C)$ for maintaining equipment operation, subscription cost (SC) for connecting the building to the electricity and/or district heating grid, as well as energy cost $(E C)$ for supplying the energy need to the building

$P V O C=\sum_{i}^{E S} P V A F \times M C_{i}+\sum_{i}^{E S} P V A F \times S C_{i}+\sum_{i}^{E S} P V A F_{e} \times E C_{i}$

where ES are the number of energy sources/systems

The $M C$ is assumed as a function of the annual operating hours. The $E C$ represents the annual energy consumption (including cost of distribution and taxes). The present values of annuity operating cost $(P V O C)$ is calculated by multiplying each annual operating cost by its Present Value Annuity Factor (PVAF) considering the discount rate ( $r$, Eq. (5)) for annual maintenance and, subscription costs $(M C$ and $S C$ ) and the discount rate $\left(r_{e}\right)$ for annual energy cost $(E C)$

PVAF $=\frac{1-\frac{1}{(1+r)^{c}}}{r}$
PVAF $_{e}=\frac{1-\frac{1}{\left(1+r_{e}\right)^{c}}}{r_{e}}$ 


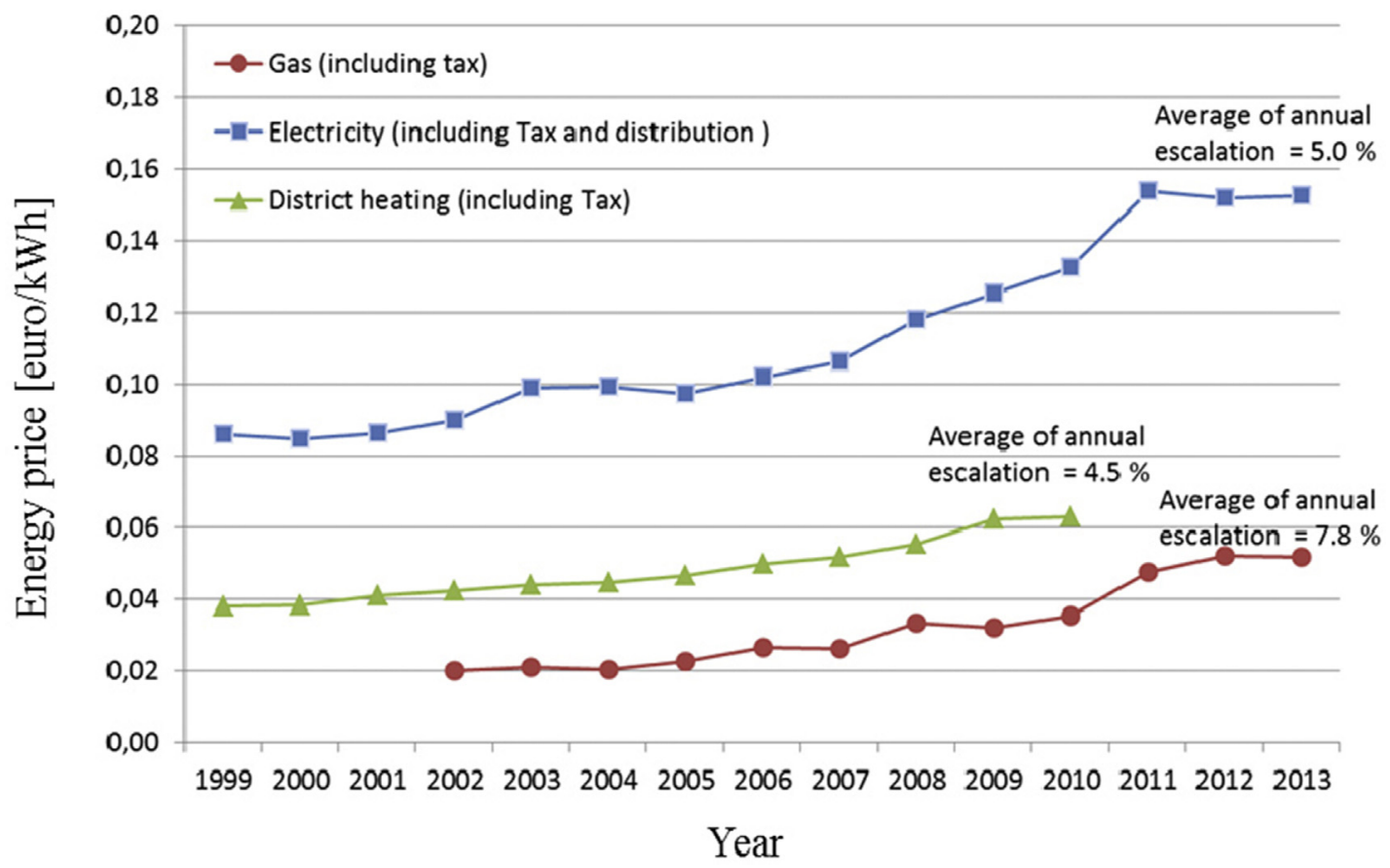

Source: [62].

Fig. 5. Historical statistic of energy price for detached household in Finland.

where $c$ is the calculation period, $r_{\mathrm{e}}$ is the discount rate (Eq. (5)) including the escalation rate of energy price $(e)$

$r_{e}=\frac{r-e}{1+e}$

In this case the cost of electrical energy is based on daytime/night rates. The daytime rate is applied on Mondays to Fridays between 07:00 and 20:00. The night time rate is applied outside these times.

The investment $(i G)$ is calculated simply by multiplying the additional investments, all costs added to improve the reference design, by the purchase discount factor $(P D F)$.

$i G=P D F \times\left(I C s-I C s_{r e f .}\right)$

The present value of residual investment $(P V R I)$ is represented by this equation

$P V R I=\sum_{i}^{R e I} \frac{1}{(1+r)^{c}} \times R V_{i}$

where $R_{e} I$ are the number of residual items

The residual value $(R V)$ of investments are calculated using the decay rate (de)

$R V=(1-d e)^{c-R T} \times I P_{r}$

where, $I P_{r}$ denotes the price of the technology at the last replacement time $(R T), \mathrm{c}$ is the calculation period

Similar to the present values of annual operating costs, the present value of annual money gain $(P V M G)$ is calculated

$P V M G=P F A F \times M G$

where $M G$ is the annuity money gain from exporting surplus electricity to the grid.

The $M G$ is calculated by multiplying the electricity price $(P e)$ by the feed-in tariff (FiT) by the amount of surplus electricity (Sur.E), generated from energy sources (ES) such as photovoltaic panels (PV) and micro-heating and power plants ( $\mu \mathrm{CHP}$ )

$M G=\sum_{i}^{E S} P e \times$ Fit $\times$ Sur. $E_{i}$

The cost-optimal energy performance level (CO-EPL) is defined as the net primary energy need (NPE, Eq. (16)) associated to the minimum life cycle cost ( $L C C_{\text {bep }}$, Eq. (1))

$\mathrm{NPE}=D P E-C F_{\text {ele }} E P E$

Where DPE and EPE are the delivered and exported primary energies, $\mathrm{CF}$ is a credit factor for exporting the surplus energy to the grid ( 0 and $1 C F$ are assumed in this study).

The delivered energies are calculated by dividing the hourly energy demands by the hourly system efficiencies and/or coefficient of performance (COP) considering the part-load operation into account (see the computational case study, Section 5). The energy demands for space heating, lighting, appliances, domestic hot water (DHW) and axillary systems (pumps and fans) is taken into account. The delivered primary energies are calculated by using non-renewable primary energy factors $P E F_{f u e l}, P E F_{D H}$, and $P E F_{\text {ele. }}$ depending on the energy carrier: fuel, district heating, and electricity, respectively

$\mathrm{DPE}=P E F_{\text {fuel }} \mathrm{Q}_{\text {fuel }}+P E F_{\mathrm{DH}} \mathrm{Q}_{\mathrm{DH}}+P E F_{\text {ele }} \mathrm{Q}_{\text {ele }}$

where $Q_{\text {fuel }}, Q_{\mathrm{DH}}$ and $Q_{\text {ele. }}$ are the delivered fuel, district heating, and electricity, respectively.

According to Finland Code of building regulation [60], 1, 0.7, and 1.7 primary energy factors (PEFs) are assumed for gas, discreet heating, and electricity, respectively.

\section{Computational case study}

The reliability of the introduced optimization-based parametric analysis scheme (Section 3), is demonstrated by investigating the cost-optimal energy performance level (CO-EPL) of a single 


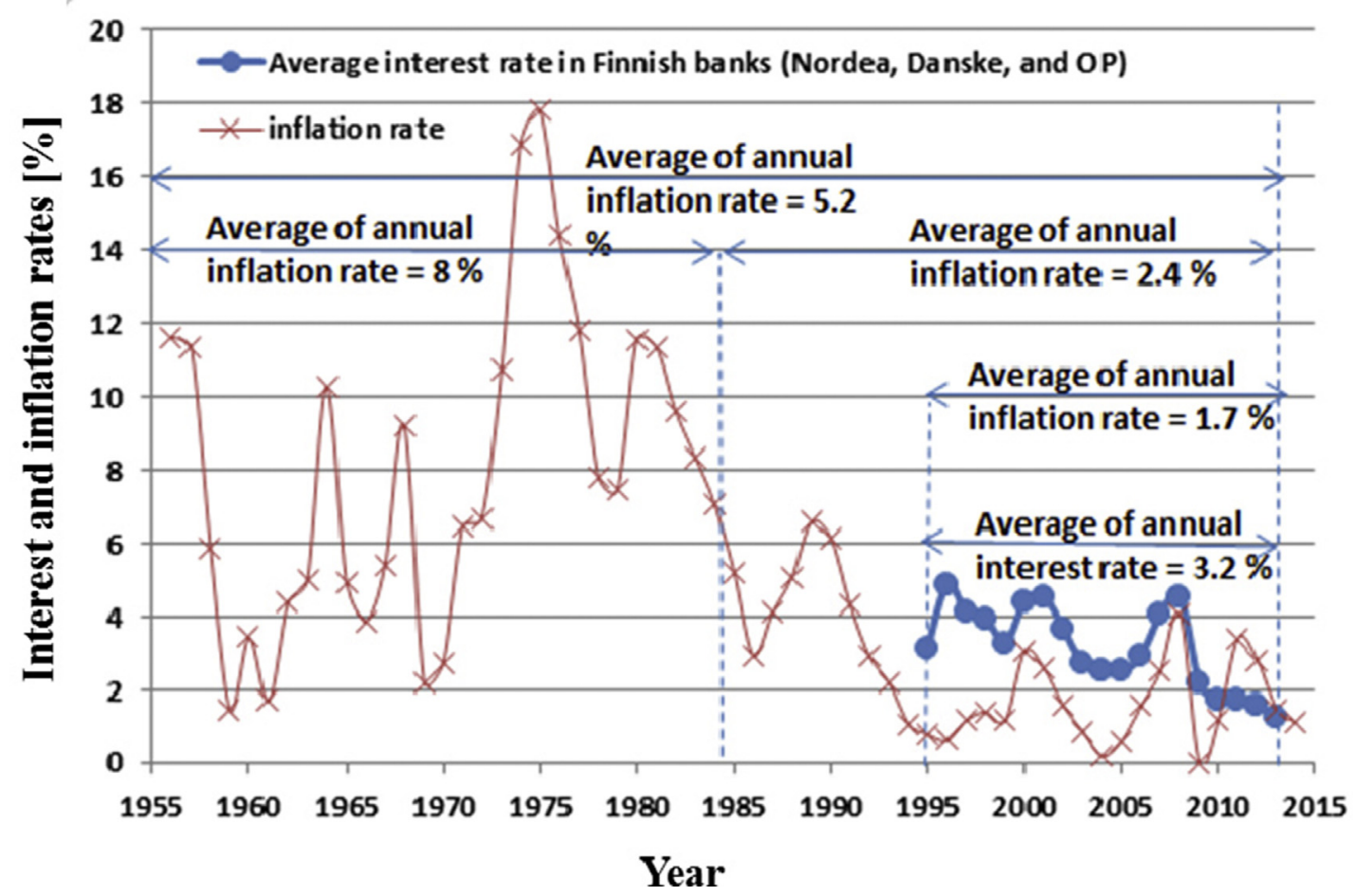

Fig. 6. Historical statistics of inflation and interest rates in Finland [63].

Table 1

Values of economic assumptions.

\begin{tabular}{ll}
\hline Economic parameters & Possible assumptions \\
\hline Nominal interest rate (i) & $(0,5,10$, or $15 \%)$ \\
Inflation rate (f) & $(-3,5$, or $7 \%)$ \\
Escalation rate of energy price (e) & $(0,4$, or $8 \%)$ \\
Calculation period (P) & $(30$ or 60 years) \\
Feed-in-tariff (FT) & $(0,50,100$, or $200 \%)$ \\
Investment grant for ESMs & $(0,20,40$, or $100 \%)$ \\
Investment grant for RETs & $(0,20,40$, or $100 \%)$ \\
\hline
\end{tabular}

Table 1 includes $4608(4 * 3 * 3 * 2 * 4 * 4 * 4)$ combinations of economic parameters' values.

family house in cold climate of Finland (see Section 4.1). Finding cost-optimal solutions for buildings in cold climate is more complex than for buildings in hot climate [61]. Climate plays a large role in determining the optimal design of a low-carbon building. Usually buildings are bespoke entities, tailored to the climate in which they are sited. For instance in general, temperate climates have most distinct solutions modes, due to the complex trade-offs that exist between cooling, heating and lighting demands. This is obvious in cold climates that have high temperature swings, thus requiring cooling as well as heating. Very hot climates have the simplest solutions, where the objective is simply to minimize solar gain. The increased effectiveness of PV in climates with high solar gain can offset the high cooling loads in those climates. This is not effective in cold climates, where other technologies may have to be investigated. Therefore in the current study, a large scale investigation is conducted assuming 1 ) a huge solutions space ranges, due to compliance with the Finnish building code [27] to solutions that realize surplus energy building (see Section 4.2) and 2) 4608 economic scenarios (Table 1) cover traditional and extreme economic assumptions in line with historical statistics data (Figs. 5 and 6) and future nZEB incentives such as feed-in tariff (FiT) and investment grant $(i G)$. Table 1 presents the assumptions of the addressed financial parameters. According to the last ten-year from Statistics

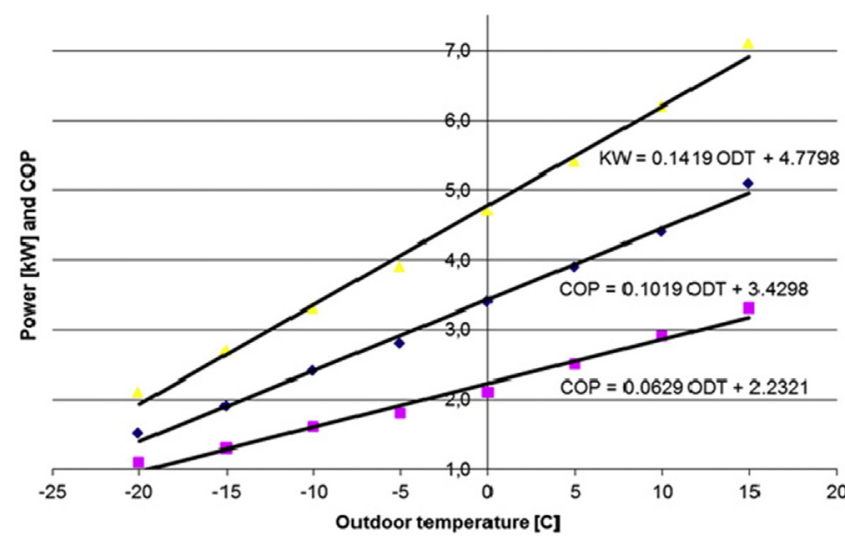

Fig. 7. Performance (COP) of the ASHP as a function of the outdoor and the supply water temperature.

Finland [20], the electricity, district heating and gas energy prices are assumed as $12.5,5$, and $3.2 € / \mathrm{kWh}$, respectively (Fig. 7).

\subsection{Description of the house and its HVAC system}

The studied house located in Helsinki Finland, and has two floors with a net floor area of $143 \mathrm{~m}^{2}$. The house is divided to 12 zones (living room, technical room, kitchen, sauna, and toilet in the ground floor; four bed rooms, common area, and toilet in the upper floor; besides staircase with opened doors between the ground and upper floor). Operable windows are installed in each zone for natural ventilative cooling when the outdoor temperature is lower than the summer threshold $25^{\circ} \mathrm{C}$ and higher than the heating set-point temperature $21^{\circ} \mathrm{C}$. Wind pressure coefficients are used from [64] to consider the wind effect on infiltration and natural ventilation of the house. No mechanical cooling is used. Internal shading control is assumed to apply the shading when the schedule is 'on' and the incident light exceeds $100 \mathrm{~W} / \mathrm{m}^{2}$ on the inside of the glass. Beside the natural cooling and internal shading, recess shading is 
Table 2

Design/operation options in the solutions space.

\begin{tabular}{|c|c|c|c|c|c|}
\hline & Parameters & $\mathrm{X}$ & Design/operation options & No. Opti-ons & Costs \\
\hline \multirow[t]{5}{*}{$\mathrm{ESM}_{\mathrm{S}}$} & $\begin{array}{l}\text { Package of building } \\
\text { envelope (PBenv.) }\end{array}$ & $\mathrm{X} 1$ & $\begin{array}{l}\text { PBenv. } 1 \text { (standard house 2010), PBenv.2 (low energy } \\
\text { house), or PBenv.3 (Passive house). }\end{array}$ & 3 & $8000 €,{ }^{a} 12,000 €,{ }^{b} 17,000 €,{ }^{c}$ \\
\hline & $\begin{array}{l}\text { Efficiency of lighting and } \\
\text { appliances }\end{array}$ & $\mathrm{X} 2$ & $\begin{array}{l}\text { Standard (Incandescent lighting + appliance energy-class } \\
\text { A) or High efficient (mix of fluorescent and Incandescent } \\
\text { lighting + energy-class A++) }\end{array}$ & 2 & $3030 €$, or $5670 €,{ }^{b}[65,66]$ \\
\hline & $\begin{array}{l}\text { Type of heat recovery unit } \\
\text { (efficiency\%) }\end{array}$ & X3 & $\begin{array}{l}\text { Cross-flow heat exchanger (60\%) Cross-flow heat } \\
\text { exchanger ( } 70 \% \text { ) Regenerative heat exchanger ( } 80 \%)\end{array}$ & 3 & $1500 €, 2000 €, 2500 €[20]^{c}$ \\
\hline & Size of buffering tank & $\mathrm{X} 4$ & $100,300,1000$, or 15001 & 4 & $370 * V_{\text {tank }}+1720[67]$ \\
\hline & $\begin{array}{l}\text { Insulation level of the } \\
\text { buffering tank }\left(\mathrm{Th}_{\text {ins }}\right)\end{array}$ & X5 & $40,100,200,400 \mathrm{~mm}$ & 4 & $150 * \mathrm{~A}_{\text {tank }} * \mathrm{Th}_{\mathrm{ins}}[68]$ \\
\hline \multirow[t]{6}{*}{ RETs } & $\begin{array}{l}\text { Area of solar thermal } \\
\text { collectors }\end{array}$ & X6 & $0,4,8,12,16,20,24$, or $28 \mathrm{~m}^{2}$ & 8 & 492 ASth + 500; Table 5 \\
\hline & $\begin{array}{l}\text { Area of photovoltaic } \\
\text { module }\end{array}$ & $\mathrm{X} 7$ & $0,4,8,12,16,20,24,28,32,36,40 \mathrm{~m}^{2}$ & 11 & 3.1Apv2 + 202A pv + 1983; Table 5 \\
\hline & $\begin{array}{l}\text { Overall efficiency of the } \\
\text { photovoltaic }\end{array}$ & $\mathrm{X} 8$ & 10 or $13 \%$ & 2 & $70 \%$ of the given price \\
\hline & & & & & $100 \%$ of the given price \\
\hline & $\begin{array}{l}\text { Slope angle of photovoltaic } \\
\text { module }\end{array}$ & X9 & $45,60,75^{\circ}$ & 3 & - \\
\hline & $\begin{array}{l}\text { Azimuth angle of } \\
\text { photovoltaic module }\end{array}$ & $\mathrm{X} 10$ & $0,15,30$ or $45^{\circ}$ from south to west. & 4 & - \\
\hline \multirow[t]{5}{*}{ Sys. } & $\begin{array}{l}\text { Type of primary heating } \\
\text { unit }\end{array}$ & $\mathrm{X} 11$ & $\begin{array}{l}\text { District heating (DH), Air source heat pump (ASHP), } \\
\text { Ground Source Heat Pump (GSHP), PEMFC with On/off } \\
\text { operating mode, or PEMFC with thermal tracing }\end{array}$ & 5 & See Table 5 \\
\hline & $\begin{array}{l}\text { Size of the primary heating } \\
\text { unit }\end{array}$ & $\mathrm{X} 12$ & $0: 0.5: 6 \mathrm{~kW}^{\mathrm{d}}$ & 13 & - \\
\hline & $\begin{array}{l}\text { Supply water temperature } \\
\text { from the primary heating } \\
\text { unit (Ts) }\end{array}$ & $\mathrm{X} 13$ & 40,50 , or $60 \%$ & 3 & - \\
\hline & Operating hour start at & $\mathrm{X} 14$ & from first of August to end of September (step 15 days) & 5 & - \\
\hline & Operating hour stop at & $\mathrm{X} 15$ & from first of May to end of June (step 15 days) & 5 & - \\
\hline
\end{tabular}

$\mathrm{V}_{\text {tank }}$ : Volume of the buffering tank $\left[\mathrm{m}^{3}\right]$.

$A_{\text {tank }}$ : Perimeter area of the buffering tank $\left[\mathrm{m}^{2}\right]$.

$\mathrm{Th}_{\text {ins }}$ : Thickness of insulation [m].

a The price is calculated based on price assumptions from our previous paper [20]. The prices are updated assuming $1.7 \%$ inflation rate (the average of the last ten year inflation rate [63]). The lifespan of the building envelope except the window is assumed to be 60 years. For windows 30 years is assumed.

b 1200 and 10,000 operating hours are assumed for the incandescent and fluorescent lighting, respectively.

c The heat recovery is replaced every 15 years.

d Direct electrical heater is assumed as a backup heating system. The size of backup system depends on the heating demands the size of the energy sources systems (e.g., primary heating system, solar thermal collector, photovoltaic) as well as the buffering tank design.

Table 3

Packages of building envelopes.

\begin{tabular}{|c|c|c|c|}
\hline Package of building envelope (PBenv.) & PBenv 1 (Standard 2010) & PBenv 2 (Low-energy house) & PBenv 3 (Passive house) \\
\hline \multicolumn{4}{|c|}{ Thermal transmittance $\mathrm{U}, \mathrm{W} /\left(\mathrm{m}^{2} \mathrm{~K}\right)$ of building envelope } \\
\hline External walls & 0.17 & 0.12 & 0.07 \\
\hline Roof & 0.09 & 0.08 & 0.06 \\
\hline Floor & 0.17 & 0.08 & 0.08 \\
\hline External doors & 1 & 0.5 & 0.4 \\
\hline Windows & 1 & 0.8 & 0.7 \\
\hline \multicolumn{4}{|l|}{ Solar properties of the windows } \\
\hline Solar heat gain coefficient ${ }^{\mathrm{a}}, \mathrm{g}$ & 0.56 & 0.56 & 0.46 \\
\hline Solar transmittance ${ }^{\mathrm{a}}, \mathrm{T}$ & 0.44 & 0.44 & 0.4 \\
\hline \multicolumn{4}{|l|}{ Air-tightness of the building envelope } \\
\hline Air change rate at $50 \mathrm{~Pa}: \mathrm{n} 50,1 / \mathrm{h}$ & 2 & 0.8 & 0.6 \\
\hline
\end{tabular}

a Internal shading of windows decreases solar heat gain coefficient by $35 \%$ and solar transmittance by $84 \%$.

implemented to minimize the summer overheating risk. In addition, overhangs are used for the south zones on the upper floor. The thermal performance of the house is evaluated by using IDAICE 4.6 [44]. In order to reduce the heating demand, exhaust-air heat recovery is used. As a reference design, the house is assumed to be connected to the district heating grid with no any on-site energy generation systems. The reference house is assumed to have minimum energy performance requirements in according to the Finnish standard [27]. The district heating plus the minimum ESMs (Table 2) cost about $21 \mathrm{k} €$. Any costs higher than this value is considered as additional investment cost (dIC). The reference design has energy performance level of $150 \mathrm{kWh} / \mathrm{m}^{2} \mathrm{a}$ which is a bit lower the standard level $170 \mathrm{kWh} / \mathrm{m}^{2} \mathrm{a}\left(372-1.4 \times\right.$ Area $\left._{\text {house }}\right)$, which has come in force by the Finnish code D3-2010 [27]. Table 3 presents the building envelope properties according the Finnish standard 2010, low energy standard, and passive house standard, respectively.

\subsection{The design and operation space (solution space)}

The solution space for cost-optimal energy performance level (CO-EPL) was based on compliance with the EPBD-recast 2010 and the Finnish national code C3-2010 to achieve nZEBs. Table 2 presents the design and operation variables which consist the solutions space: three packages of building envelope (Benv 1, Benv 2 , 
Table 4

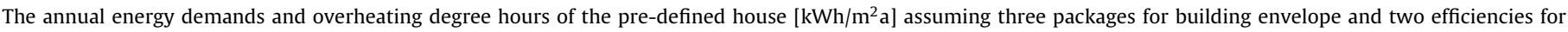
equipment (lighting and appliance).

\begin{tabular}{|c|c|c|c|c|c|c|c|}
\hline & \multirow{2}{*}{$\begin{array}{l}\text { Package of building envelope (PBenv.) } \\
\text { Lighting and appliances efficiency }\end{array}$} & \multicolumn{2}{|l|}{ PBenv 1} & \multicolumn{2}{|l|}{ PBenv 2} & \multicolumn{2}{|l|}{ PBenv 3} \\
\hline & & Standard & High & Standard & High & Standard & High \\
\hline \multirow{5}{*}{ Heating Demands [kWh/m²a] } & Space heating in zones & 39.2 & 45.2 & 22.2 & 26.8 & 8.3 & 12.1 \\
\hline & Heating of ventilation air & 10.1 & 10.5 & 10.1 & 9.9 & 8.6 & 9.6 \\
\hline & Heating of DHW & 31.9 & 31.9 & 31.9 & 31.9 & 31.9 & 31.9 \\
\hline & storage and distribution loss & 3.3 & 3.3 & 3.3 & 3.3 & 3.3 & 3.3 \\
\hline & Total & 84.5 & 91.0 & 67.5 & 72.0 & 52.0 & 57.0 \\
\hline \multirow{5}{*}{$\begin{array}{l}\text { Basic Electrical Demands } \\
{\left[\mathrm{kWh} / \mathrm{m}^{2} \mathrm{a}\right]}\end{array}$} & Lighting & 7.3 & 3.7 & 7.3 & 3.7 & 7.3 & 3.7 \\
\hline & Equipment, appliances & 28.7 & 21.5 & 28.7 & 21.5 & 28.7 & 21.5 \\
\hline & Sauna & 6.7 & 4.6 & 6.7 & 4.6 & 6.7 & 4.6 \\
\hline & Fans, pumps & 5.6 & 5.6 & 5.6 & 5.6 & 5.7 & 5.7 \\
\hline & Total & 48.5 & 35.5 & 48.5 & 35.5 & 48.5 & 35.5 \\
\hline \multirow{3}{*}{$\begin{array}{l}\text { Total Electrical Demands } \\
\text { (Heating + Basic) }\left[\mathrm{kWh} / \mathrm{m}^{2} \mathrm{a}\right]\end{array}$} & if GSHP is used & 86.2 & 75.2 & 81.8 & 69.9 & 77.6 & 66.2 \\
\hline & if $A W H P$ is used & 110.9 & 101.2 & 102.8 & 91.8 & 95.3 & 85.1 \\
\hline & if Ele. Boiler is used & 132.8 & 126.2 & 115.9 & 107.3 & 100.6 & 92.5 \\
\hline Overheating degree hours $\left(\mathrm{DH}_{27}\right)\left[{ }^{\circ} \mathrm{Ch}\right]$ & & 47.8 & 31.1 & 49.9 & 31.2 & 88.6 & 31.4 \\
\hline
\end{tabular}

and Benv 3) range from in according to the 2010 standard (Benv1) to passive house in according to RIL-2009 Finnish codes (Benv3); standard and high efficient equipment (lightings and appliances); cross flow and regenerative heat recovery units; four sizes of storage tank; three levels of storage tank insulation; eight sizes $(0,4$, $8,12,16,20,24$, or $28 \mathrm{~m}^{2}$ ) of solar thermal collectors; eleven sizes of photovoltaic; two types of photovoltaic module (thin film and mono-cSi); three and four options for slope and azimuth angles of the PV modules (inclination angles from 45 to $75^{\circ}$ and orientations from south to west), five types of primary heating systems (EleB: electrical boiler, DH: District Heating, ASHP: Air Source Heat Pump, GSHP: Ground Source Heat Pump, or $\mu \mathrm{CP} / \mu \mathrm{PEMFC}$ ); five sizes for the primary heating unit; three levels water supply; six starting and six stopping times for the primary heating unit. The design variables are classified into three categories:

1. Energy saving measures (ESMs): measures which reduce the energy demand (from $\mathrm{X}_{1}$ to $\mathrm{X}_{6}$ ),

2. Renewable energy technologies (RETs): technologies which use sustainable sources of energy like wind and sun (from $\mathrm{X}_{7}$ to $\mathrm{X}$ 13),

3. Mechanical systems (SYSs): mechanical systems which can be used if $100 \%$ sustainable sources of energy are unavailable via RETs (from $\mathrm{X}_{14}$ to $\mathrm{X}_{16}$ ),

Table 3 describes the three building envelope packages: the package of standard house (PBenv1), the package of low energy house (PBenv2), and the package of passive house (PBenv3). Table 4 presents the energy use and the overheating level in the three representative building envelope packages assuming two cases: standard and high efficient "ighting and appliances" are implemented.

Table 5 presents the installation and maintenance costs of the energy supply systems (solar thermal collector, photovoltaic, and primary heating system) as well as their lifespan and their related annual subscription/energy delivering fees.

\subsection{Example of implementation}

Fig. 9 illustrates the implementation of the introduced multitool calculation engine (the core of the OptnZEB-I, Fig. 4, the core of the optimization-based parametric analysis scheme, Fig. 3) for handling the predefined computational case study (Section 4). Multi tools (dynamic software such as IDA-ICE and IDA-ESBO as well as simplified models based manufacturing data and/or steady state

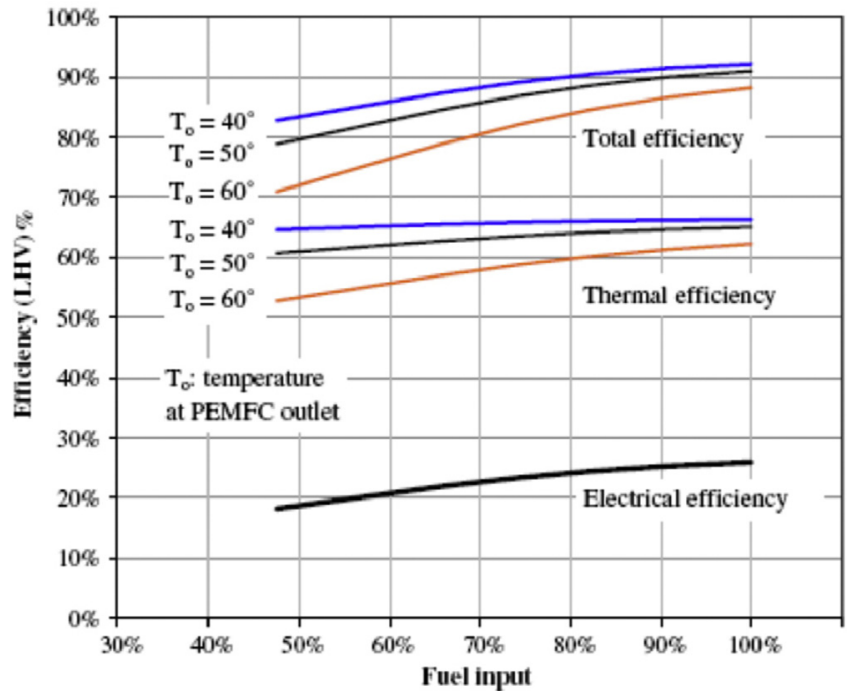

Fig. 8. Electrical (AC to grid), thermal and total efficiency performance characteristics of 4.6 kWe PEMFC device [75].

heat balance modelling, Fig. 9) are utilized to calculate the energy consumption and generation in relation to the integrated building design. Detailed dynamic simulations -by IDA-ICE and IDA-ESBOare used to assess the performance of implementing new options of building envelope/lighting and photovoltaic/solar thermal system. The detailed simulation results are kept in archives to be used for post-processing evaluations considering the whole integrated building and system design. The possibility of avoiding sophisticated and/or detailed simulations and using post-processing instead is managed by the OptnZEB-I by asking "is there a need for detailed simulation", see Fig. 4. The answer of this question is given to the engine by identifying the particular design variables' combinations which require detailed simulation using detailed dynamic simulations as shown below.

The multi-tool calculation engine (Fig. 9) divides the solution spaces into a number of subsets of inputs (Yellow input boxes) to execute the required tool only at each evaluation during the optimization run. The first subset (the first input box) includes the design parameters with direct influence on the thermal performance of the building the first two design variables: package of building envelope $\left(\mathrm{X}_{1}\right)$ and efficiency of appliances and lighting $\left(\mathrm{X}_{2}\right)$ \}. IDA-ICE 4.6, a detailed building performance simulation 


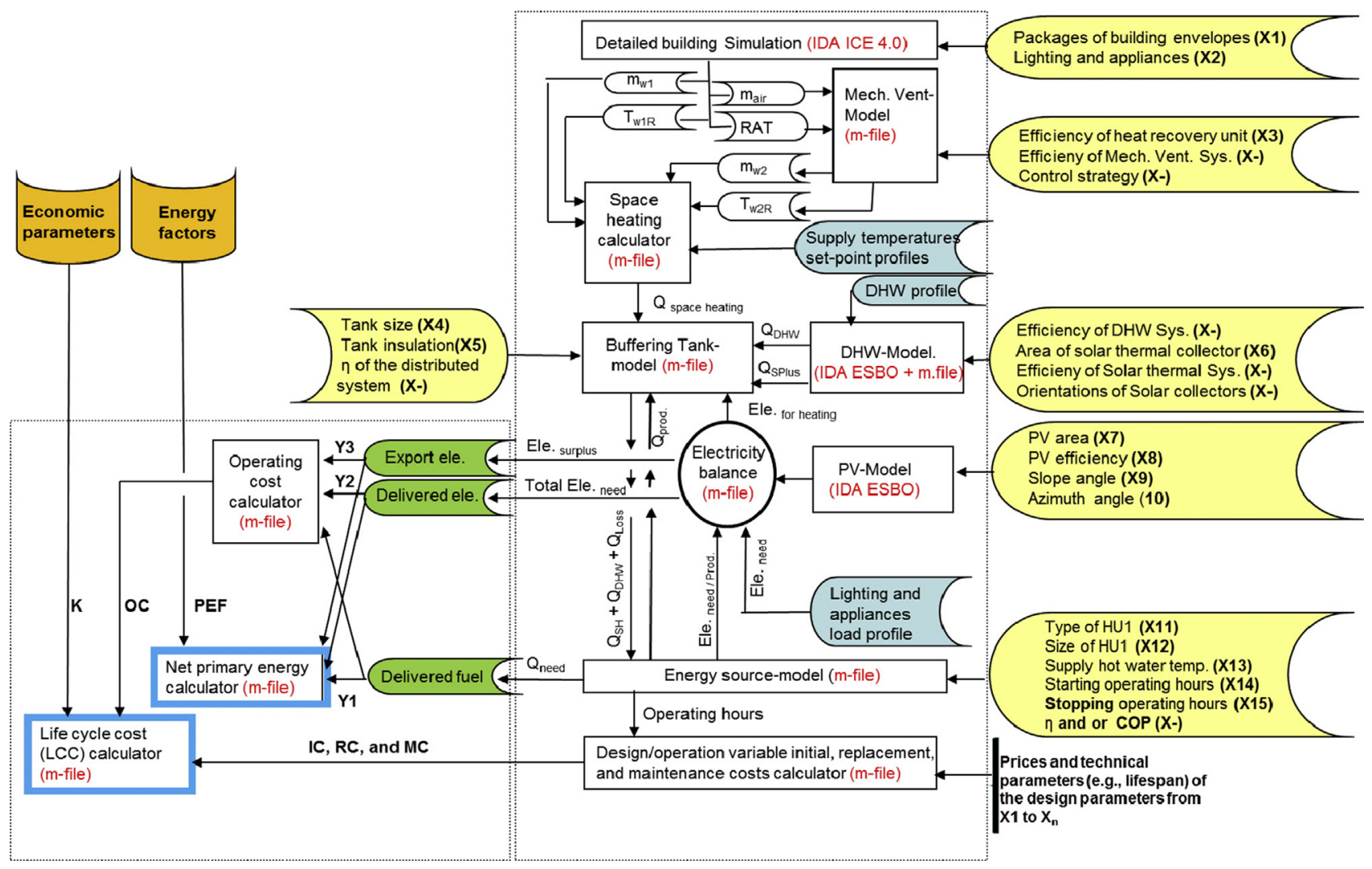

Fig. 9. The new concept of multi-tool calculation engine based on [1] (the main core of OptnZEB_I shown in).

tool, runs only corresponding to changes of those variables $\left(\mathrm{X}_{1}\right.$ and $\mathrm{X}_{2}$ ). A simplified models such as AHU-model is executed -instead IDA-ICE 4.6- to evaluate the influence of improving the efficiency of the heat recovery $\left(\mathrm{X}_{3}\right)$ and efficiency of the AHU fan (X-) on the energy need. The AHU-model relies on pre-simulated results (return air temperature (RAT) and mass flow rate $\left(\mathrm{m}_{\text {air }}\right)$ ) from detailed simulations carried out by IDA-ICE 4.6. Using the AHU-model avoids running many of time-consuming detailed simulations. It is a simplified model with a very short execution time (less than $0.01 \mathrm{~s}$ ) which is ready to run instead the IDA-ICE 4.6 when detailed pre-simulated results (RAT, $\mathrm{m}_{\mathrm{air}}$ ) are available in the OptnZEB-I's archive.

Time-expensive simulations are also avoided in the following cases. The potential of heating energy saving due to increasing the buffering tank capacity $\left(\mathrm{X}_{4}\right)$, increasing the storage tank insulation $\left(\mathrm{X}_{5}\right)$, implementing thermal solar collector $\left(\mathrm{X}_{6}\right)$, and/or utilizing the surplus electricity generation (e.g., from PV) is calculated using a simplified one-node tank model. The model is created to be utilized instead of detailed simulation by applying semi-state hourly heat balance equation. This aims to calculate the water temperature inside the tank depending on different energy supply sources and different energy conservation measures. The operational temperature of the tank ranges between 60 and $90^{\circ} \mathrm{C}$. If the size of the primary heating units is not sufficient to achieve the $60^{\circ} \mathrm{C}$, the auxiliary electrical heaters work to keep the tank at the minimum temperature level. The impact of the return water temperature of space heating system $\left(\mathrm{m}_{\mathrm{w} 1}\right)$ and AHU $\left(\mathrm{m}_{\mathrm{w} 2}\right)$ on the performance of the heating systems are considered into calculations. The heat losses from the buffering and DHW tanks are calculated according to the Finnish regulation D3-2012 [27] as functions of the hot water storage capacity (size of buffering take $\left(\mathrm{X}_{4}\right)+$ size of DHW tank) as well as the insulation level $\left(\mathrm{X}_{5}\right)$. Detailed simulation is applied using IDA-ESBO to assess the potential of solar thermal collect for DHW energy saving. The DHW tank has a set-point temperature of $55^{\circ} \mathrm{C}$.
The tank is heated by three means: solar heating, controlled heating from buffering tank, and auxiliary electrical heater, consequently. The tank has a size of 3001 . The solar thermal collectors are used mainly to reduce the domestic hot water demands. Depending on the temperature limits, the surplus solar heating - generated in the DHW tank - can transfer to the buffering tank to be utilized for space heating. The electricity generated from RETs (like photovoltaic) is used mainly to cover the lighting, appliances, and plug load demands.

The PV-model calls IDA-ESBO to evaluate hourly electrical production of one square meter of photovoltaic. Scaling factors are used to adapt the hourly electricity production when $\mathrm{X}_{7}$ and/or $\mathrm{X}_{8}$ are changed. The PV-model calls IDA-ESBO only when the slope or the azimuth angles $\left(\mathrm{X}_{9}\right.$ and $\left.\mathrm{X}_{10}\right)$ of the PV modules are changed. The $\mu \mathrm{CHP}$-model is a simplified model uses manufacture performance curves to evaluate the performance of $\mu \mathrm{CHP}$, Fig. 9. The electrical productions from PV and $\mu \mathrm{CHP}$ and the electrical use (appliances, lighting, and indirect electrical heating) are fed to the electrical balance model (Electricity balance-model). The model is used to calculate the electrical matching indices and the delivered $\left(\mathrm{Y}_{2}\right)$ and export $\left(\mathrm{Y}_{3}\right)$ electricity.

The OptnZEB-I's calculation scheme follows the Trias Energetica principle to provide sustainable energy utilization [76,77] (see Fig. 10). The primary heating unit $\left(\mathrm{X}_{11}\right)$ is used when the direct RETs and are not able to cover the building demands. The electrical heater is used as a backup system. The energy source-model evaluates the performance of the primary and auxiliary energy source units. The primary heating units (e.g., ASHP and GSHP) operate at varying COP depending on part load ratio (PLR, Fig. 11) and environmental impact such as outdoor temperatures (ODT). Example of the variation of the COP of the ASHP and the GSHP is shown in Fig. 12. The figure shows the variation considering the impacts of the part load factor, outdoor temperature as well as supply temperate. 
Table 5

Energy supply systems.

\begin{tabular}{|c|c|c|c|c|c|c|c|c|c|}
\hline & \multirow[t]{2}{*}{ Technical systems } & \multicolumn{2}{|c|}{$\begin{array}{l}\text { Efficiency }(\eta) \text { or coefficient of } \\
\text { performance (COP) }\end{array}$} & \multicolumn{2}{|l|}{ Installation cost $(€)$} & \multicolumn{2}{|c|}{ Life expectancy } & \multicolumn{2}{|l|}{ Annual costs } \\
\hline & & $\eta$ & $\mathrm{COP}$ & Unit cost & Initial setup cost & Unit & Install-ation & $\begin{array}{l}\text { period } \\
\text { maintenance cost }\end{array}$ & $\begin{array}{l}\text { Annual } \\
\text { subscription/delivering } \\
\text { fees }(€)^{\mathrm{a}}\end{array}$ \\
\hline \multirow[t]{2}{*}{ Solar systems } & Solar thermal (Sth) & Variant $\mathrm{b}^{\mathrm{b}}$ & - & $492 A_{\text {sth }}$ & 500 & 15 & 30 & $46.7 \mathrm{~A}_{\mathrm{Sth}}$ & 0 \\
\hline & Photovoltaic (PV) & 10 or $13 \%$ (optional) & - & $3.1 A_{p v}{ }^{2}+202 A_{p v}+1983[67]$ & & 30 & 30 & $46.7 \mathrm{APV}_{\mathrm{PV}}[70]$ & 0 \\
\hline \multirow[t]{5}{*}{ Heating systems } & Electrical boiler & $100 \%$ & - & $200 \mathrm{~kW}+700[69]$ & 300 & 10 & 60 & $0 € /$ Wh & 0 \\
\hline & District heating (DH) & $93 \%$ & - & $50.5 \mathrm{~kW}$ & 6050 & 15 & 60 & $1.1 € / \mathrm{Wh}$ & 445.6 \\
\hline & Air source heat pump (ASHP) & - & Variant Fig. 8 & $285 \mathrm{~kW}+5615[70]$ & 615 & 15 & 60 & $14 € / \mathrm{Wh}$ & 0 \\
\hline & Ground source heat pump (GSHP) & - & Variant & $285 \mathrm{~kW}+6615[70]$ & $771 \mathrm{~kW}+842[71]$ & 15 & 60 & $14 € / \mathrm{Wh}$ & 0 \\
\hline & $\begin{array}{l}\mu \mathrm{CHP} \text { (Proton exchange membrane } \\
\text { fuel cell (PEMFC) }\end{array}$ & Variant Fig. 9 & - & $7000 \mathrm{kWe}[72]$ & 1.7 unit cost & 4.6 & 15 & $16 € / \mathrm{Wh}$ & 720 \\
\hline
\end{tabular}

an addition to the $85.2 €$ Annual electricity subscription fee [73].

bVariant according to the DHW temperature. The simulation is made by IDA-ESBO, a dynamic simulation tool.

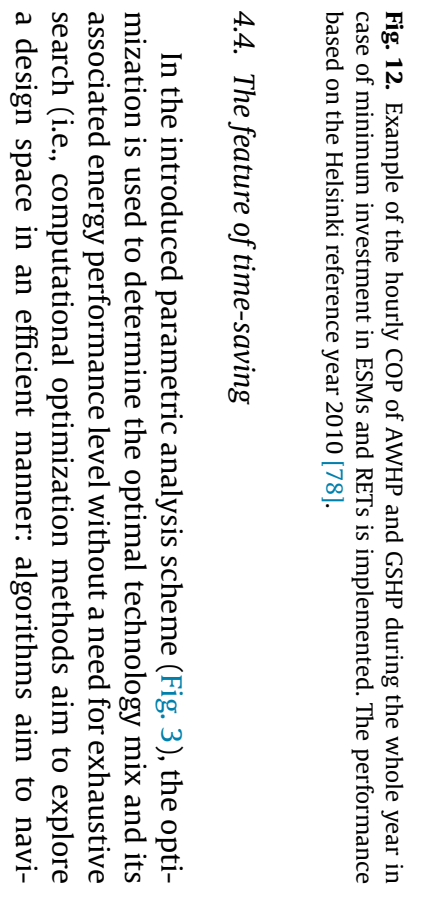
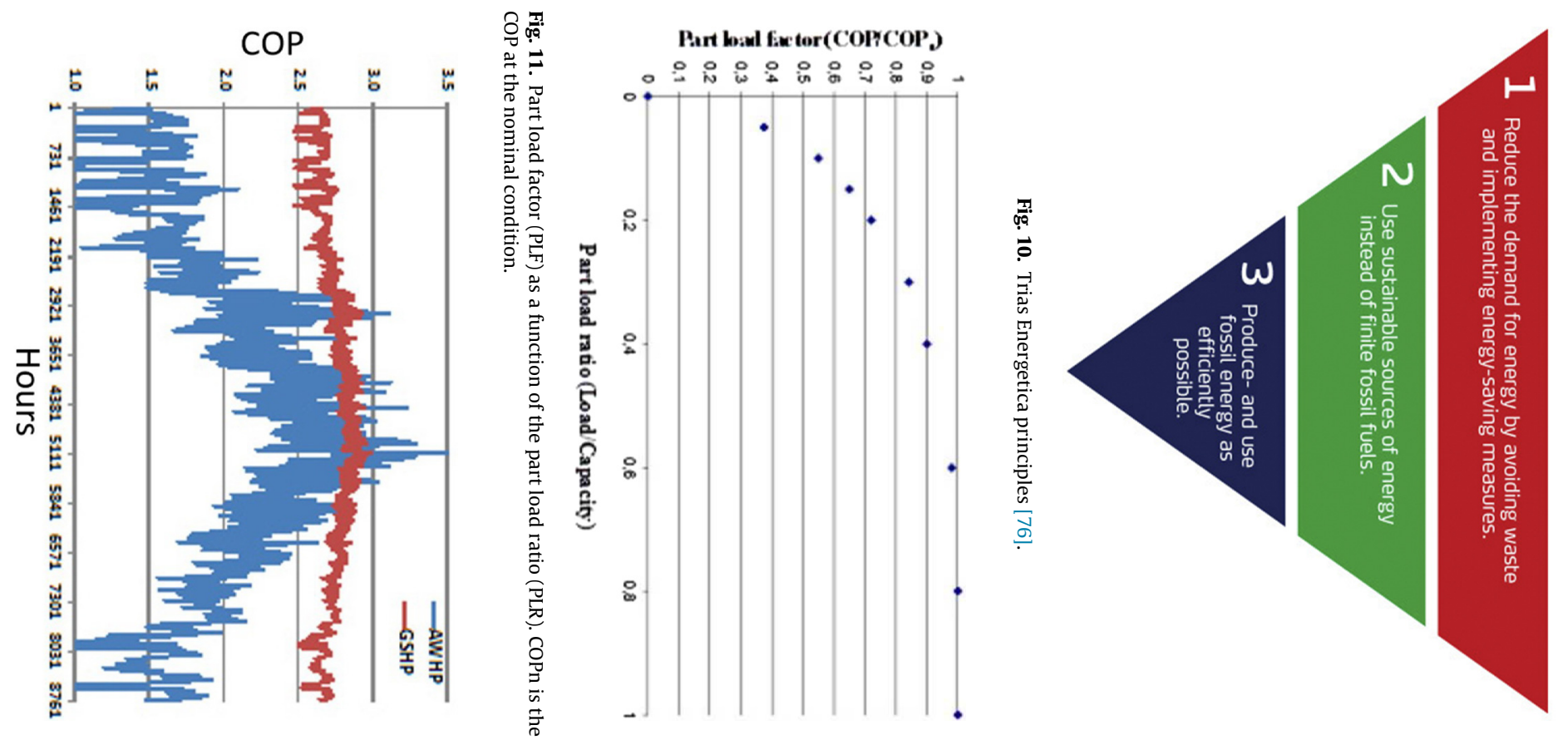
gate quickly to the best solutions). In addition to the time-saving feature of applying computational optimization, the optimization is speeded up by avoiding sophisticated and detailed simulations when was possible. Detailed/time-consuming simulations are run only when there was a need as shown in Fig. 4.

This section gives an example of the time-saving which can be achieved by our novel simulation-based optimization concept (using simulations only when needed). The example presents the optimization of the base-case assumptions ( $i=3.2 \%, f=1.7 \%, e=5 \%$, $d=5 \%, F i T=0$, and $I G=0$ ).

If traditional simulation-based optimization approach was used, there was a need to perform 39, 90, and 94 detailed/timeconsuming simulations for evaluating the building envelope options 1, 2 and 3, respectively, during the optimization run. With our novel simulation-based optimization concept (Section 3.2), only few simulations were enough for each building envelope option. In this example, the detailed building performance simulation is used only thirteen times instead of $223(39+90+94)$ times: two times for simulating the first building envelope option (PBenv 1 ), five times for simulating the second building envelope option (PBenv 2), and six times for simulating the third building envelope option (PBenv 3) considering the interaction between the building envelope and the lighting and appliances as well as the heat recovery options (the design variables' options which influence directly the thermal performance of the house). For instance, there was no need to simulate the first building envelope option (PBenv 1) more than two times, because there was no interaction between PBenv 1 and the lighting -appliances option 2 either the heat recovery option 2.

Moreover, there was no interaction between the (PBenv2 + Lighting \& appliance 2) and the heat recovery option. This reduced the computation time significantly following the this equation

Time saving $=\sum_{i}^{N 1} \tau_{i}-\sum_{i}^{N 2} \tau_{i} \approx \tau_{\text {average }}\left(N_{1}-N_{2}\right)$

Where $\tau$ is the average execution time of one detailed building simulation using IDA-ICE $(\approx 0.6 \mathrm{~h})$. $\mathrm{N}_{1}$ and $\mathrm{N}_{2}$ the number of evaluations required by the traditional and the novel simulation-based optimization concepts (223, and 13 ), respectively.

\section{Results and discussion}

\subsection{Pre-parametric analysis}

Before investigating the impact of the financial assumptions on the CO-EPL, parametric analysis is carried out to check the maximum and minimum potentials of reducing the delivered energy by implementing available options of ESMs (Fig. 13), and RETs (Fig. 14). The maximum potential represents the maximum energy reduction can be achieved by implementing a specific ESM or RET option when minimum implementations are considered for the other ESMs and RET and direct electrical boiler is assumed for heating. The minimum potential represents the minimum energy reduction can be achieved by implementing a specific ESM or RET when maximum implementations of other ESMs and RETs options are assumed with a large size (6 kW) GSHP for heating.

The results show that the maximum implementations of RET ( $40 \mathrm{~m}^{2}$ of photovoltaic) can reduce the basic electrical demands ( 48.4 and $35.4 \mathrm{kWh} / \mathrm{m}^{2}$ a where standard and high efficient lighting \& appliances options are assumed, respectively) by about $25 \%$ (11.6 and $9.5 \mathrm{kWh} / \mathrm{m}^{2} \mathrm{a}$, respectively). In case of the heating demand is covered by indirect electrical-based heating systems (ASHP and GSHP), the $40 \mathrm{~m}^{2} \mathrm{PV}$ can achieve additional energy reduction ranges from 5.1 to 8.4 in case of ASHP, and $3.7-7.2, \mathrm{kWh} / \mathrm{m}^{2} \mathrm{a}$ in case

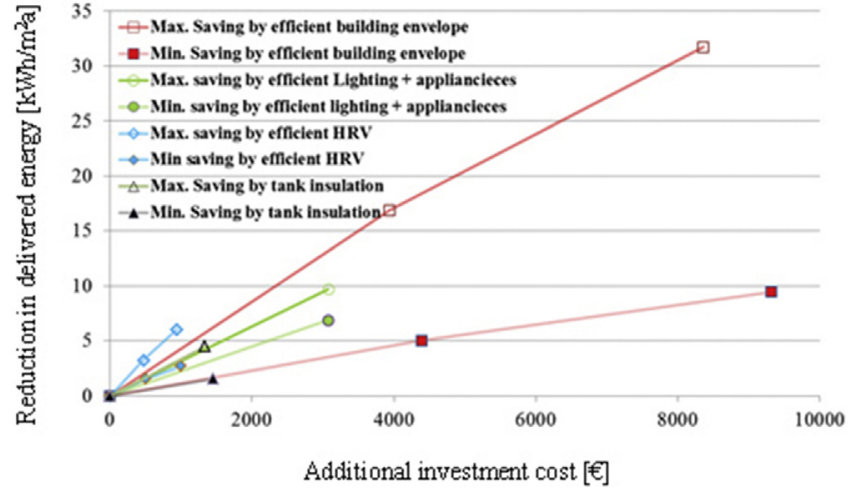

Fig. 13. The potential of available ESMs options (Table 2) in reducing the delivered energy (in terms of electricity import).

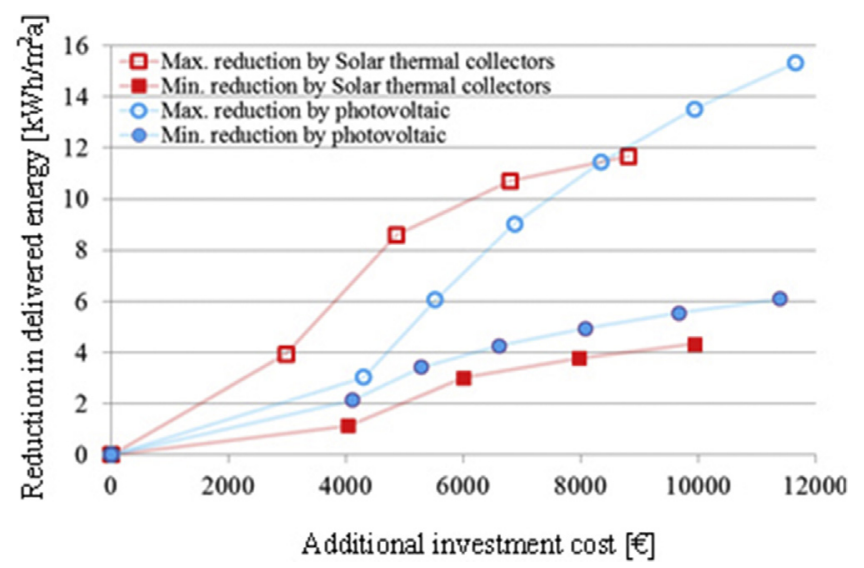

Fig. 14. The potential of RETs options (Table 2 ) in reducing the delivered energy (in terms of electricity import).

of GSHP. The highest and lowest reductions $\left(8.4,7.2 \mathrm{kWh} / \mathrm{m}^{2} \mathrm{a}\right)$ and $\left(5.1,3.7 \mathrm{kWh} / \mathrm{m}^{2} \mathrm{a}\right)$ are corresponding to the efficiency of the implemented lighting and appliances (standard and high efficient, respectively) where minimum implementation of other RET (e.g., no solar thermal collector) and ESMS (e.g., 60\% efficient heat recovery unit, and $40 \mathrm{~mm}$ insulation thickness) are assumed. The impact of maximum implementations of other ESMs and RETs (e.g., 80\% efficient heat recovery unit, $200 \mathrm{~mm}$ insulation thickness, and $28 \mathrm{~m}^{2}$ solar thermal collectors) on the potential of energy reduce by high efficient lighting \& appliances and/or the PV is shown in Figs. 13 and 14, respectively.

\subsection{Impact of financial assumptions on the cost optimality towards nZEB (optimization-based parametric analysis results)}

The sensitivity of the cost-optimal energy performance level (CO-EPL, Figs. 15 and 16) and the cost-optimal investment (CO-IC, Figs. 17 and 18$)$ to the escalation rate of energy price $(e)$ and the discount rate $(r)$ are investigated where "there is no" and "there is" FiT as well as "there is no" and "here is" $i G$ (25\% discount of additional investment). Two regression slopes $\left(a_{1}\right.$ and $\left.a_{2}\right)$ are calculated to present the sensitivity of the cost optimal level (y-axis) to the discount rate ' $r$ ' $(x$-axis), where $r>0 \%$ and $r<0 \%$, respectively as shown in Figs. 16 and 18. Examples of detailed global cost-optimal solutions are shown by Table 5 which presents the investment costs (IC) of each implemented technology, the present value of replacement cost (PVRC), the percent value of energy cost (PVEC), as well as the net primary energy with and without credit for exporting the surplus energy to the grid. In general, the results show that the energy 
Table 6

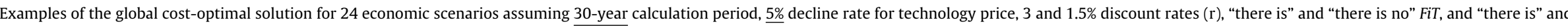
"there is no" investment grant $(i G)$ and $1 \%, 5 \%$ and $10 \%$ energy price escalation rates (e).

\begin{tabular}{|c|c|c|c|c|c|c|c|c|c|c|c|c|c|}
\hline Discount rate & \multicolumn{6}{|c|}{ Discount rate $(r=3)[\%]$} & \multicolumn{7}{|c|}{ Discount rate $(r=3)[\%]$} \\
\hline Calculation Period & \multicolumn{6}{|c|}{ Calculation Period 30 Year } & \multicolumn{7}{|c|}{ Calculation Period 30 Year } \\
\hline Investment grant & \multicolumn{6}{|c|}{ No investment grant } & \multicolumn{7}{|c|}{ Investment grant $=25 \%$ of dIC } \\
\hline Declime rate of tech. Price & \multicolumn{6}{|c|}{ Declime rate of tech. Price $=5 \%$} & \multicolumn{7}{|c|}{ Declime rate of tech. Price $=5 \%$} \\
\hline Feed-in-tariff & \multicolumn{3}{|c|}{ FiT $=0$} & \multicolumn{3}{|l|}{$\mathrm{FiT}=1$} & \multicolumn{3}{|c|}{ FiT $=0$} & \multicolumn{4}{|l|}{$\mathrm{FiT}=1$} \\
\hline Escalation of energy price & $1 \%$ & $5 \%$ & $10 \%$ & $1 \%$ & $5 \%$ & $10 \%$ & $1 \%$ & $5 \%$ & $10 \%$ & $1 \%$ & $5 \%$ & $10 \%$ & Average \\
\hline 'Building envelope[Euro]' & 7841 & 17151 & 17151 & 7841 & 12231 & 7841 & 12231 & 17151 & 17151 & 12231 & 17151 & 7841 & 12818 \\
\hline 'Lighting + appliances [Euro]' & 3030 & 5670 & 5670 & 3030 & 5670 & 5670 & 3030 & 5670 & 5670 & 3030 & 5670 & 5670 & 4790 \\
\hline 'Heat recovery [Euro]' & 1500 & 2500 & 1500 & 1500 & 2500 & 1500 & 1500 & 2500 & 1500 & 1500 & 2500 & 1500 & 1833 \\
\hline 'Buffering tank [Euro]' & 1799 & 1838 & 1799 & 1799 & 1838 & 1909 & 1838 & 1838 & 1799 & 1838 & 1838 & 1799 & 1828 \\
\hline 'Solar collecor [Euro]' & 0 & 0 & 0 & 0 & 0 & 0 & 0 & 0 & 0 & 0 & 0 & 0 & 0 \\
\hline 'Photovoltiac [Euro]' & 0 & 0 & 0 & 0 & 0 & 0 & 0 & 0 & 0 & 0 & 0 & 0 & 0 \\
\hline 'Inverter [Euro]’' & 0 & 0 & 443 & 0 & 0 & 665 & 0 & 0 & 443 & 0 & 0 & 1108 & 222 \\
\hline ‘Heating System [Euro]’ & 13202 & 11791 & 17587 & 13202 & 12968 & 26336 & 12899 & 11791 & 17587 & 12044 & 11791 & 42714 & 16993 \\
\hline Total investment [Euro]' & 27372 & 38951 & 44150 & 27372 & 35207 & 43921 & 31498 & 38951 & 44150 & 30643 & 38951 & 60632 & 38483 \\
\hline 'dLCC [Euro/m2]' & -9 & -49 & -315 & -9 & -39 & -456 & -21 & -80 & -355 & -21 & -80 & -493 & -161 \\
\hline 'LCC [Euro/m2]' & 437 & 608 & 893 & 437 & 617 & 752 & 428 & 580 & 857 & 428 & 580 & 719 & 611 \\
\hline 'IC [\% of LCC]' & $44 \%$ & $45 \%$ & $35 \%$ & $44 \%$ & $40 \%$ & $41 \%$ & $52 \%$ & $47 \%$ & $36 \%$ & $50 \%$ & $47 \%$ & $59 \%$ & $45 \%$ \\
\hline 'PVRC [\%]' & $5 \%$ & $5 \%$ & $7 \%$ & $5 \%$ & $5 \%$ & $11 \%$ & $5 \%$ & $5 \%$ & $7 \%$ & $5 \%$ & $5 \%$ & $8 \%$ & $6 \%$ \\
\hline 'PVMC + PVSC [\%of LCC]' & $8 \%$ & $6 \%$ & $15 \%$ & $8 \%$ & $6 \%$ & $19 \%$ & $7 \%$ & $6 \%$ & $16 \%$ & $7 \%$ & $6 \%$ & $20 \%$ & $10 \%$ \\
\hline 'PVEC [\% of LCC]' & $44 \%$ & $45 \%$ & $44 \%$ & $44 \%$ & $49 \%$ & $58 \%$ & $41 \%$ & $47 \%$ & $46 \%$ & $42 \%$ & $47 \%$ & $68 \%$ & $48 \%$ \\
\hline 'PViG [\% of LCC]' & $0 \%$ & $0 \%$ & $0 \%$ & $0 \%$ & $0 \%$ & $0 \%$ & $-4 \%$ & $-5 \%$ & $-4 \%$ & $-3 \%$ & $-5 \%$ & $-9 \%$ & $-3 \%$ \\
\hline 'PVRI [\% of LCC]' & $-0,4 \%$ & $-0,4 \%$ & $-0,4 \%$ & $-0,4 \%$ & $-0,4 \%$ & $-0,6 \%$ & $-0,5 \%$ & $-0,4 \%$ & $-0,4 \%$ & $-0,4 \%$ & $-0,4 \%$ & $-0,8 \%$ & $-0,5 \%$ \\
\hline ‘PVMG [\% of LCC]' & $0 \%$ & $0 \%$ & $0 \%$ & $0 \%$ & $0 \%$ & $-29 \%$ & $0 \%$ & $0 \%$ & $0 \%$ & $0 \%$ & $0 \%$ & $-46 \%$ & $-6 \%$ \\
\hline 'Operating hours of PHU' & 3637 & 3265 & 3661 & 3637 & 2756 & 3932 & 2908 & 3265 & 3661 & 4103 & 3265 & 2505 & 3383 \\
\hline NPE (no credit) [kWh/m2]' & 141 & 96 & 63 & 141 & 107 & 72 & 127 & 96 & 63 & 131 & 96 & 81 & 101 \\
\hline NPE (with credit) [kWh/m2]' & 141 & 96 & 47 & 141 & 107 & 39 & 127 & 96 & 47 & 131 & 96 & 31 & 92 \\
\hline Discount rate & \multicolumn{6}{|c|}{ Discount rate $(r=1.5)[\%]$} & \multicolumn{7}{|c|}{ Discount rate $(r=1.5)[\%]$} \\
\hline Calculation Period & \multicolumn{6}{|c|}{ Calculation Period 30 Year } & Calcula & eriod 30 & & & & & \\
\hline Investment grant & No inve & t grant & & & & & Investn & $\operatorname{rant}=25$ & & & & & \\
\hline Declime rate of tech. Price & Declim & of tech. $\mathrm{P}$ & & & & & Declim & of tech. P & & & & & \\
\hline Feed-in-tariff & $\mathrm{FiT}=0$ & & & $\mathrm{FiT}=1$ & & & $\mathrm{FiT}=0$ & & & $\mathrm{FiT}=1$ & & & \\
\hline Escalation of energy price & $1 \%$ & $5 \%$ & $10 \%$ & $1 \%$ & $5 \%$ & $10 \%$ & $1 \%$ & $5 \%$ & $10 \%$ & $1 \%$ & $5 \%$ & $10 \%$ & Average \\
\hline ‘Building envelope[Euro]' & 7841 & 17151 & 17151 & 7841 & 17151 & 7841 & 12231 & 17151 & 17151 & 12231 & 17151 & 7841 & 13228 \\
\hline 'Lighting + appliances [Euro]' & 3030 & 5670 & 5670 & 3030 & 5670 & 5670 & 3030 & 5670 & 5670 & 3030 & 5670 & 5670 & 4790 \\
\hline 'Heat recovery [Euro]' & 1500 & 2500 & 2000 & 1500 & 1500 & 1500 & 1500 & 2500 & 1500 & 1500 & 1500 & 1500 & 1708 \\
\hline 'Buffering tank [Euro]' & 1838 & 1838 & 1799 & 1838 & 1799 & 2176 & 1838 & 1838 & 1799 & 1838 & 1799 & 1767 & 1847 \\
\hline 'Solar collecor [Euro]' & 0 & 0 & 0 & 0 & 0 & 0 & 0 & 0 & 0 & 0 & 0 & 0 & 0 \\
\hline 'Photovoltiac [Euro]' & 0 & 0 & 0 & 0 & 0 & 0 & 0 & 0 & 0 & 0 & 0 & 5084 & 424 \\
\hline 'Inverter [Euro]’ & 0 & 0 & 443 & 0 & 443 & 886 & 0 & 0 & 443 & 0 & 443 & 1538 & 350 \\
\hline 'Heating System [Euro]' & 13201 & 11791 & 17587 & 13201 & 17587 & 34531 & 12899 & 11791 & 17587 & 12899 & 17587 & 42726 & 18616 \\
\hline Total investment [Euro]' & 27410 & 38951 & 44650 & 27410 & 44150 & 52605 & 31498 & 38951 & 44150 & 31498 & 44150 & 66126 & 40962 \\
\hline 'dLCC [Euro/m2]' & -24 & -105 & -529 & -24 & -112 & -737 & -41 & -136 & -566 & -41 & -154 & -787 & -271 \\
\hline 'LCC [Euro/m2]' & 500 & 717 & 1103 & 500 & 711 & 895 & 487 & 689 & 1069 & 487 & 671 & 848 & 723 \\
\hline 'IC [\% of LCC]' & $38 \%$ & $38 \%$ & $28 \%$ & $38 \%$ & $44 \%$ & $41 \%$ & $45 \%$ & $40 \%$ & $29 \%$ & $45 \%$ & $46 \%$ & $55 \%$ & $41 \%$ \\
\hline 'PVRC [\%]' & $5 \%$ & $5 \%$ & $7 \%$ & $5 \%$ & $11 \%$ & $13 \%$ & $5 \%$ & $6 \%$ & $7 \%$ & $5 \%$ & $11 \%$ & $9 \%$ & $8 \%$ \\
\hline 'PVMC + PVSC [\%of LCC]' & $9 \%$ & $6 \%$ & $15 \%$ & $9 \%$ & $24 \%$ & $21 \%$ & $8 \%$ & $6 \%$ & $16 \%$ & $8 \%$ & $25 \%$ & $29 \%$ & $15 \%$ \\
\hline 'PVEC [\% of LCC]' & $48 \%$ & $51 \%$ & $50 \%$ & $48 \%$ & $31 \%$ & $75 \%$ & $45 \%$ & $53 \%$ & $52 \%$ & $45 \%$ & $32 \%$ & $73 \%$ & $50 \%$ \\
\hline 'PViG [\% of LCC]' & $0 \%$ & $0 \%$ & $0 \%$ & $0 \%$ & $0 \%$ & $0 \%$ & $-3 \%$ & $-4 \%$ & $-4 \%$ & $-3 \%$ & $-6 \%$ & $-9 \%$ & $-2 \%$ \\
\hline 'PVRI [\% of LCC]' & $-0,6 \%$ & $-0,5 \%$ & $-0,5 \%$ & $-0,6 \%$ & $-0,8 \%$ & $-1,2 \%$ & $-0,6 \%$ & $-0,5 \%$ & $-0,5 \%$ & $-0,6 \%$ & $-0,8 \%$ & $-1,0 \%$ & $-0,7 \%$ \\
\hline 'PVMG [\% of LCC]' & $0 \%$ & $0 \%$ & $0 \%$ & $0 \%$ & $-9 \%$ & $-48 \%$ & $0 \%$ & $0 \%$ & $0 \%$ & $0 \%$ & $-9 \%$ & $-56 \%$ & $-10 \%$ \\
\hline 'Operating hours of PHU' & 3618 & 3265 & 3452 & 3618 & 3661 & 3259 & 2908 & 3265 & 3661 & 2908 & 3661 & 2550 & 3319 \\
\hline NPE (no credit) [kWh/m2]' & 140 & 96 & 62 & 140 & 63 & 78 & 127 & 96 & 63 & 127 & 62 & 73 & 94 \\
\hline NPE (with credit) [kWh/m2]' & 140 & 96 & 47 & 140 & 47 & 32 & 127 & 96 & 47 & 127 & 46 & 22 & 81 \\
\hline
\end{tabular}




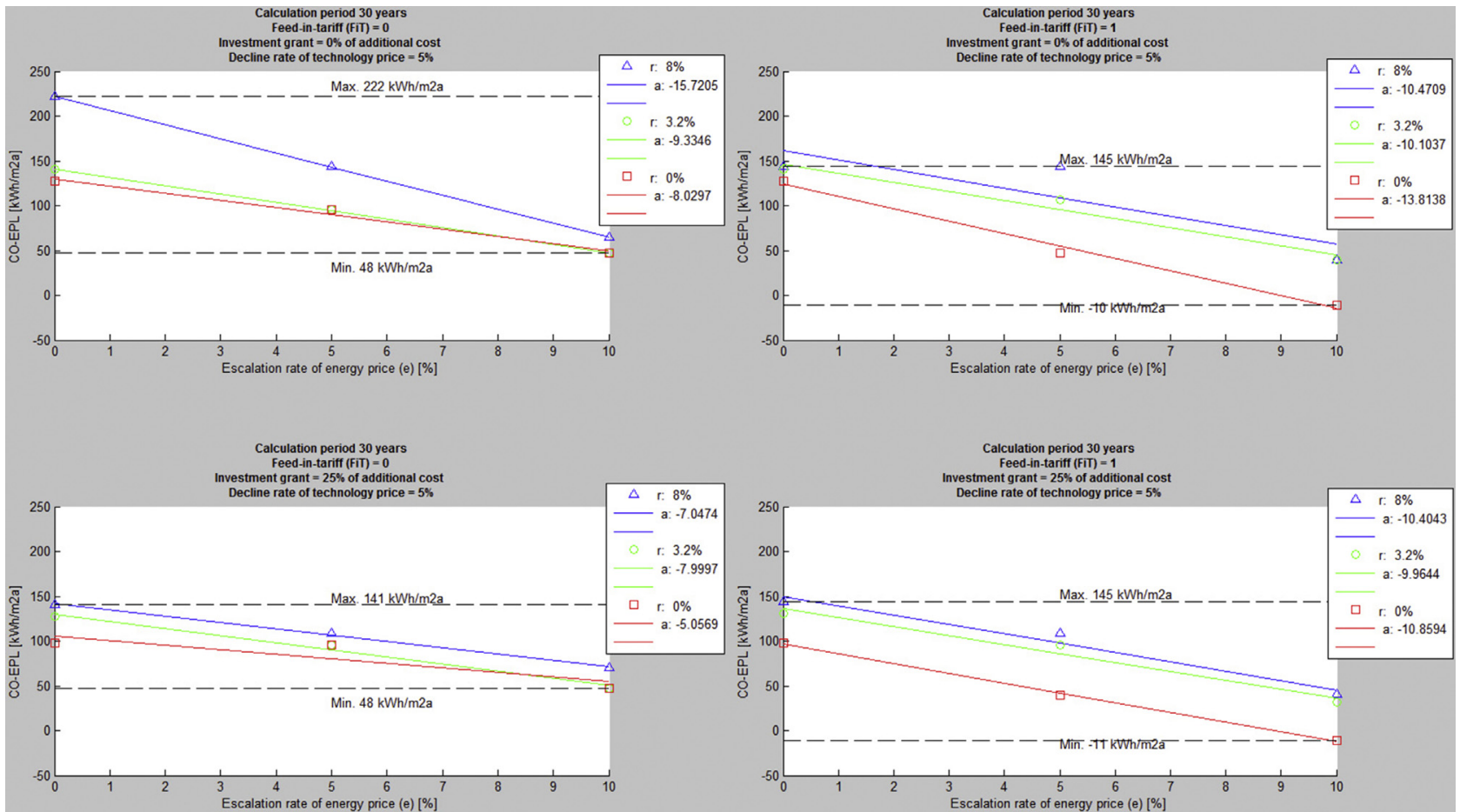

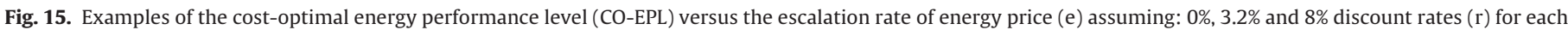

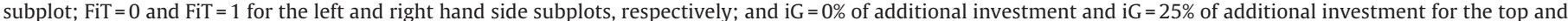
bottom subplots, respectively. Where 30 -year calculation period is assumed. Energy credit (100\% credit) is given for exporting the surplus energy to the grid.

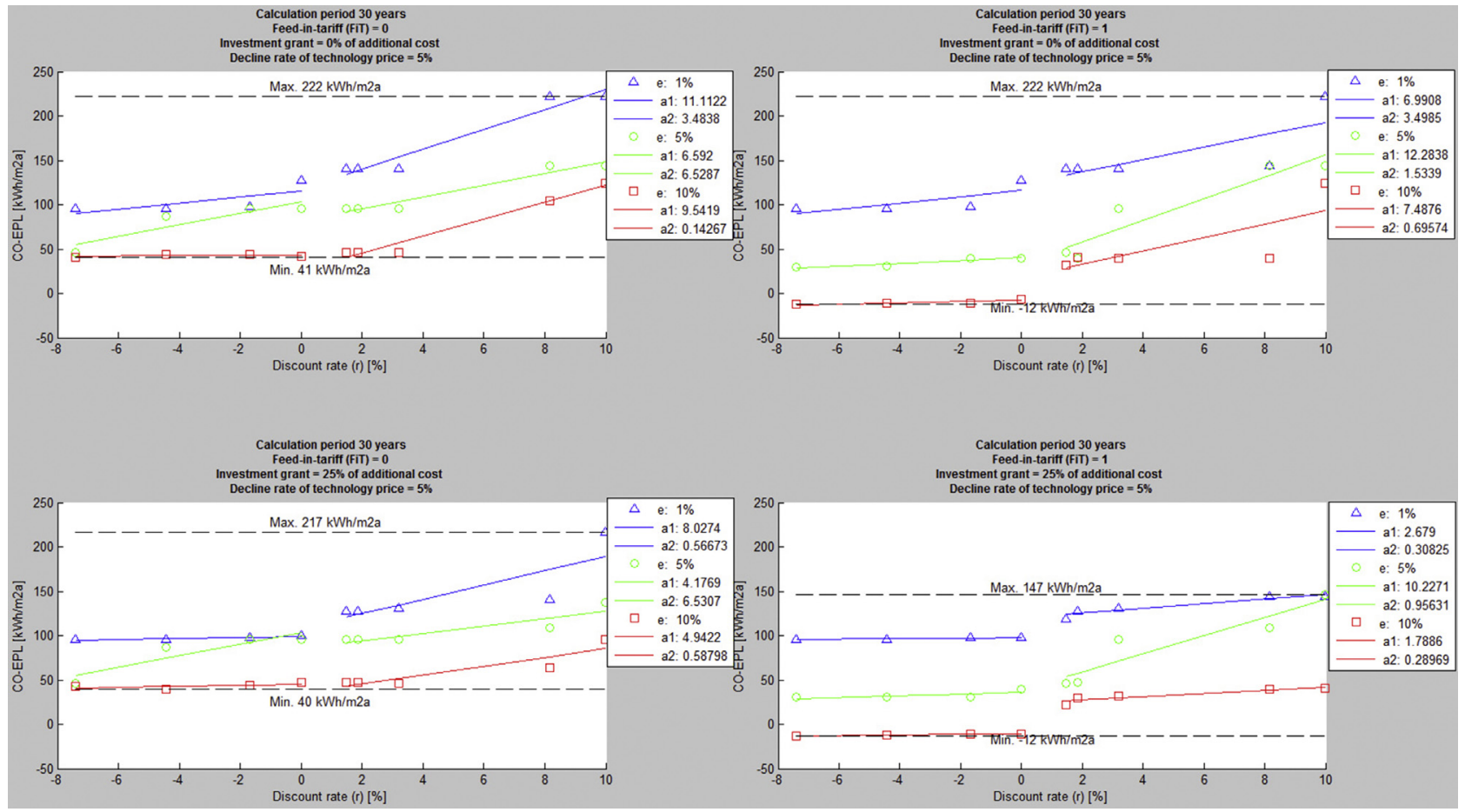

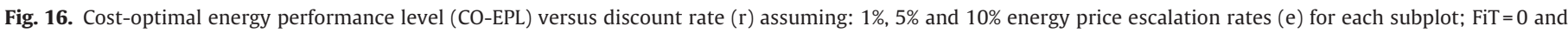

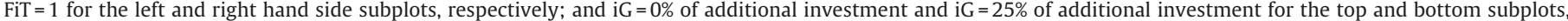
respectively. Where 30 -year calculation period is assumed. Energy credit (100\% credit) is given for exporting the surplus energy to the grid.

price escalation rate $(e)$, the discount rate $(r)$, and then the FiT are the most influenced financial parameters on the CO-EPL (Table 6).

- The sensitivity of the cost-optimal energy performance level $(C O-E P L)$ to the escalation rate of energy price (e) depends on the discount rate (r) as well as the other financial assumptions (e.g., FiT and iG) as shown in Fig. 13. The CO-EPL decreases as long as the escalation rate (e) increases. The decline rate $\left(\mathrm{a}_{\mathrm{CO}-\mathrm{EPL} / \Delta \mathrm{e}}=\Delta \mathrm{CO}-\mathrm{EPL} / \Delta \mathrm{e}\right)$ ranges from -5 to 13.8 and from -7 to $-15.7 \mathrm{kWh} / \mathrm{m}^{2}$ a per $\Delta \mathrm{e} \%$, where $r=0$ and $8 \%$, respectively. 


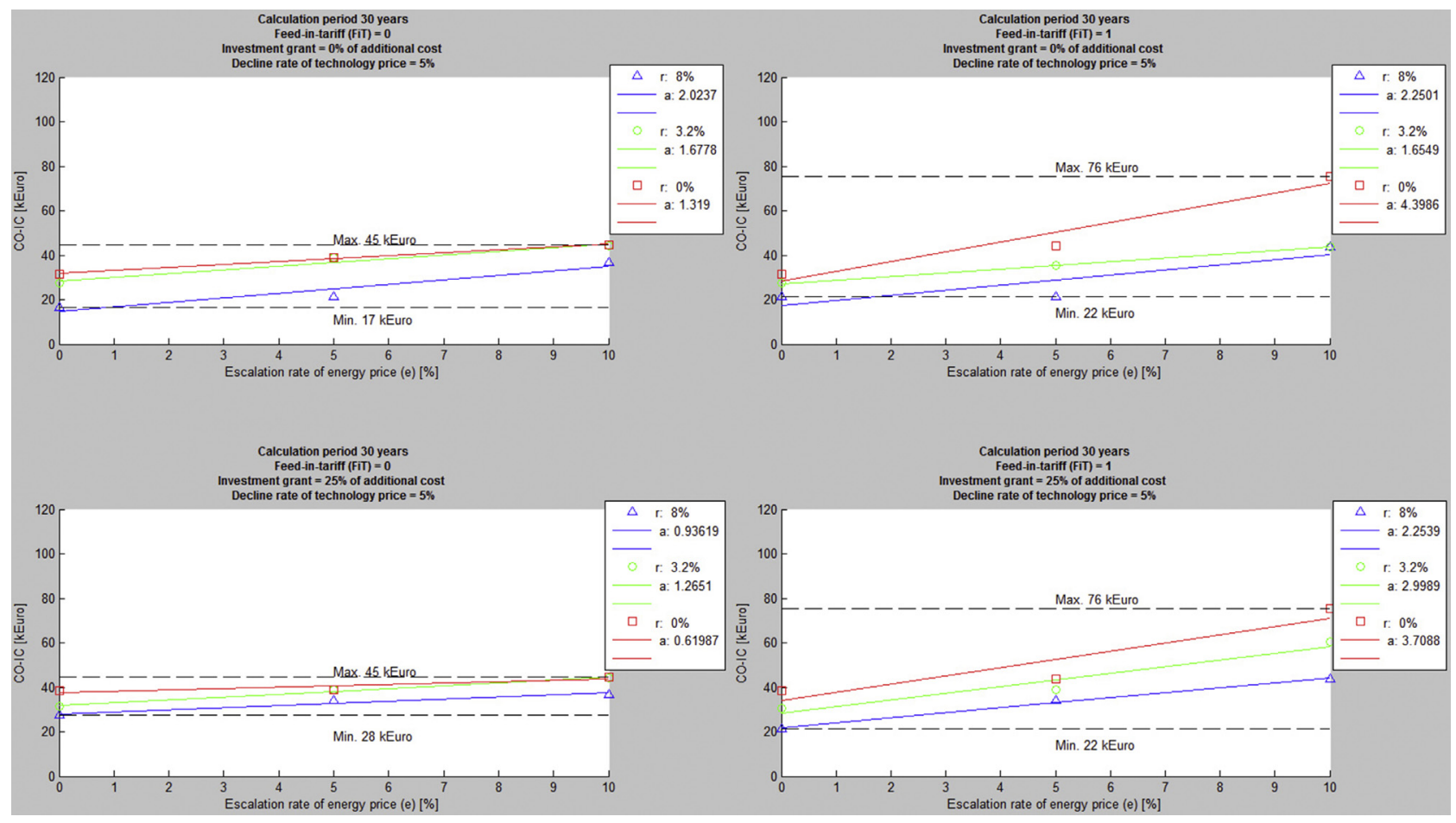

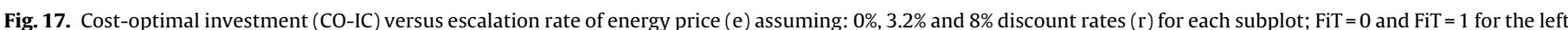

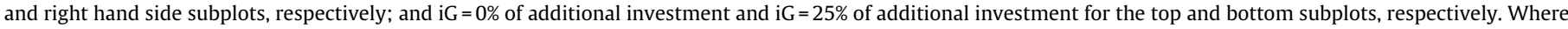
30 -year calculation period is assumed.
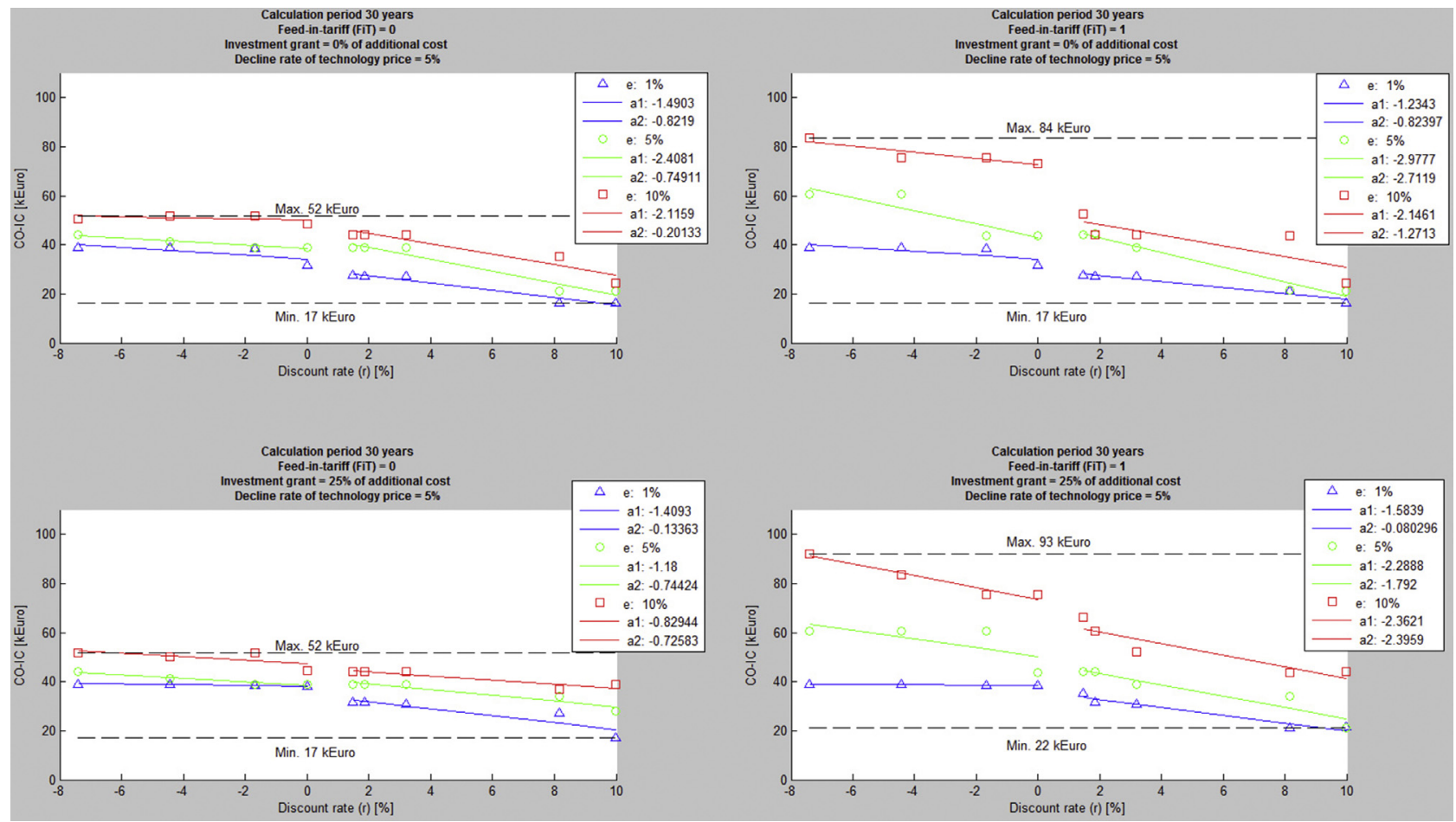

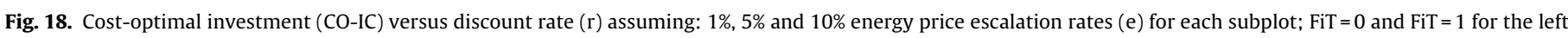

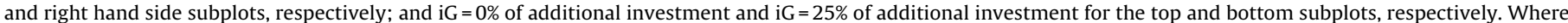
30 -year calculation period is assumed.

- The sensitivity the cost-optimal energy performance level (CO$E P L)$ to the discount rate (r) depends significantly on the energy price escalation rate $(e)$ as well as the other financial assumptions (e.g., FiT and $i G$ ), Fig. 14. The CO-EPL increases as long as the discount rate decreases. The escalation rate $\left(a_{\mathrm{CO}-\mathrm{EPL} / \Delta r}=\Delta C O\right.$ $E P L / \Delta r$ ) ranges from 1.8 to $12.3 \mathrm{kWh} / \mathrm{m}^{2} \mathrm{a}$ and from 0.14 to $6.5 \mathrm{kWh} / \mathrm{m}^{2}$ a per $\Delta r \%$, where $\mathrm{r}>0$ and $\mathrm{r} \leq 0$, respectively. 
- The sensitivity the cost-optimal investment $(\mathrm{CO}-\mathrm{IC})$ to the escalation rate of energy price $(e)$ depends on the discount rate $(r)$ as well as the other financial assumptions (e.g., FiT and $i G$ ). The $\mathrm{CO}-$ $I C$ increases as long as the escalation rate $(e)$ increases, Fig. 15. The escalation rate $\left(a_{\mathrm{CO}-\mathrm{IC}}=\Delta \mathrm{CO}-\mathrm{IC} / \Delta \mathrm{e}\right)$ could ranges from 0.6 to 4.4 and from 0.94 to $2.25 \mathrm{k} €$ per $\Delta \mathrm{e} \%$, where $r=0$ and $8 \%$, respectively.

- The sensitivity the cost-optimal investment (CO-IC) to the discount rate $(r)$ depends significantly on the energy price escalation rate as well as the other financial assumptions (e.g., FiT and $i G$ ). The CO-IC decreases as long as the discount rate increases, Fig. 16. The decline rate $\left(a_{\mathrm{CO}-\mathrm{IC}}=\Delta \mathrm{CO}-\mathrm{IC} / \Delta \mathrm{r}\right)$ could ranges from -0.83 to $-2.97 \mathrm{k} € / \Delta \mathrm{r}$ and from 0.1 to $-2.7 \mathrm{k} € / \Delta \mathrm{r}$, where $\mathrm{r}>0$ and $\mathrm{r} \leq 0$, respectively.

\section{Conclusion}

A novel optimization-based parametric analysis scheme is introduced for applying fast and detailed investigation on cost-optimal towards nZEBs. The reliability of the scheme is demonstrated by investigating a large scale problem (i.e., deign of nZEB where 2,965,248,000 design solutions and 4608 economic scenarios are possible). to the results show the scheme's features that include time-saving feature of applying computational optimization versus applying exhaustive search speeding up the optimization process by avoiding sophisticated and detailed simulations when is possible. The outcomes demonstrate that the presented scheme is a robust tool for taking care of extensive scale cost-optimality investigations.

The introduced scheme can determine the cost-optimal solution at any financial assumptions with a sufficient accuracy. The results show that:

- The financial parameters which affect the annual operating costs $(e, r$, and then the FiT) are the most influenced ones on the CO-EPL. The sensitively of the CO-EPL to the $e, r$, and FiT rates range from -5.1 to $-15.6 \mathrm{kWh} / \mathrm{m}^{2}$ a per $\Delta \mathrm{e} \%$, from +0.15 to $+12.3 \mathrm{kWh} / \mathrm{m}^{2} \mathrm{a}$ per $\Delta \mathrm{r} \%$, and from -0.1 to $-0.5 \mathrm{kWh} / \mathrm{m}^{2}$ a per $\Delta F i T \%$ depending on the other financial assumptions. In average, the CO-EPL ranges from 90 to $160\left[\mathrm{kWh} / \mathrm{m}^{2}\right]$. The range has most frequent value of $145 \mathrm{kWh} / \mathrm{m}^{2}$.

- The investment grant (25\% discount of additional investment) could not be needed as an incentive, if low discount $(r \leq 1.5 \%)$ and/or high escalation ( $e \geq 5 \%)$ are assumed.

- The low $r$ and high $e$ are enough to encourage environmentallyfriendly investments. The FiT could be unattractive incentive, if high discount rate $(r \geq 1.5 \%)$ and/or low escalation rate $(\mathrm{e}<5 \%)$ are assumed particularly where no $i G$ is offered.

Finally it is important to mention that EU Member States should first set up minimum energy performance thresholds for nZEBs and then perform (and update) their cost-optimality calculation every five years. If the cost-optimal scenarios result on cost-optimal energy performance level (CO-EPL) ranges are higher than the minimum energy performance thresholds then national governments should intervene and provide incentives to lower the (CO-EPL) ranges to meet the minimum energy performance thresholds and environmental targets for nZEBs as shown in Fig. 1. However, many Southern and Eastern European member states did not define their nZEBs energy performance requirements for new or existing buildings. As a consequence, the calculation of $C O-E P L$ is not possible and a many member states encounter high decision uncertainty on the impact of Financial Assumptions on the Cost Optimality towards Nearly Zero Energy in Existing Buildings.

\section{Future work}

In this study, we presented the robustness of our optimizationbased parametric analysis scheme (OPtnZEB-I) for analysing the cost-optimality towards nZEBs. The future work will aim at determining the most promising nZEB economic drivers (e.g., soft loans, deduction in technology price, etc.,) for promoting deep building renovation from property owner and other stakeholder's points of views. Dynamic prices as well as dynamic energy conversion factors will be implemented according to national and international statistics. The impact of the dynamic behavior on the economic and ecological results will be compared with the traditional fixed annual assumption. In order to generalize the results, different cases will be addressed considering different climates, economic scenarios, as well as occupant behaviors.

\section{References}

[1] M. Hamdy, K. Sirén, A multi-aid optimization scheme for large-scale investigation of cost-optimality and energy performance of buildings, J. Build. Perform. Simul. 9 (4) (2016) 411-430.

[2] G. Kumbaroglua, R. Madlener, Evaluation of economically optimal retrofit investment options for energy savings in buildings, Energy Build. 49 (2012) 327-334.

[3] A. Hasan, M. Vuolle, K. Siren, Minimisation of life cycle cost of a detached house using combined simulation and optimization, Build. Environ. 43 (12) (2008) 2022-2034

[4] A.M. Papadopoulos, T.G. Theodosiou, K.D. Karatzas, Feasibility of energy saving renovation measures in urban buildings: the impact of energy prices and the acceptable payback time criterion, Energy Build. 34 (5) (2002) 455-466.

[5] L. Georges, C. Massart, G. Moeseke, A. De Herde, Environmental and economic performance of heating systems for energy-efficient dwellings: case of passive and low-energy single-family houses, Energy Policy 40 (1) (2012) 452-464.

[6] J. Kurnitskia, A. Saari, T. Kalamees, M. Vuolle, J. Niemela, T. Tark, Cost optimal and nearly zero (nZEB) energy performance calculations for residential buildings with REHVA definition for nZEB national implementation, Energy Build. 43 (11) (2011) 3279-3288.

[7] A.J. Marszal, P. Heiselberg, R.L. Jensen, J. Nørgaard, On-site or off-site renewable energy supply options: life cycle cost analysis of a net zero energy building in Denmark, Renew. Energy 44 (2012) 154-165.

[8] M. Munjur, J. Maula, M. Hamdy, T. Fang, N. Jung, R. Lahdelma, Researching social acceptability of renewable energy technologies in Finland, Int. J. Sustain. Built Environ. 2 (June (1)) (2013) 89-98, http://dx.doi.org/10.1016/j. ijsbe.2013.10.001, ISSN 2212-6090.

[9] S. Attia, Towards regenerative and positive impact architecture: a comparison of two net zero energy buildings, Sustain. Cities Soc. 26 (2016) 393-406 http://dx.doi.org/10.1016/j.scs.2016.04.017, ISSN 2210-6707.

[10] The Directive 2010/31/EU of the European Parliament and of the Council of 19 May 2010 on the energy performance of buildings (recast), Off. J. Eur. Union (2010) 13-35, available at: http://eur-lex.europa.eu/LexUriServ/LexUriServ. do? uri=OJ:L:2010:153:0013:0035:EN:PDF.

[11] B. Atanasiu, 2013 Implementing the cost-optimal methodology in EU countries: Lessons Learned from three case studies The Buildings Performance Institute Europe (BPIE), March 2013.

[12] EC, European Commission. "Delegated Regulation (EU) No 244/2012 of 16 January 2012 supplementing Directive 2010/31/EU of the European Parliament and of the Council on the energy performance of buildings by establishing a comparative methodology framework for calculating cost-optimal levels of minimum energy performance requirements for buildings and building elements". Available at: http://eur-lex.europa.eu/ LexUriServ/LexUriServ.do? uri=OJ:L:2012:081:0018:0036:EN:PDF (2012).

[13] The European Committee for Standardization (CEN).

[14] EN-15459, Energy Performance of Buildings, Economic Evaluation Procedure for Energy Systems in Buildings, 2007.

[15] BPIE Cost-optimality. Discussing methodologies and challenges within the recast Energy performance of Buildings Directive. Available at: http://www. bpie.eu/documents/BPIE/BPIE_costoptimality_publication2010.pdf (2010).

[16] R.D. Coninck, G. Verbeeck, Technical-Economic Analysis of the cost effectiveness of Energy Saving Investments. Technical Report, Brussels Institute for the Management of the Environment, Final Report, August (2005).

[17] G. Verbeeck, H. Hens, Life cycle optimization of extremely low energy dwellings, J. Build. Phys. 31 (2007) 143.

[18] A. Audenaert, S.D. Cleyn, B. Vankerckhove, Economic analysis of passive houses and low-energy houses compared with standard houses, Energy Policy 36 (2008) 47-55.

[19] K. Achten, R.D. Coninck, G. Verbeeck, J. Van der Veken, Analyzing the economic feasibility of permutations of energy-saving measures with batch simulations and Pareto optimization, in: Eleventh International IBPSA Conference, Glasgow, Scotland, 2009. 
[20] M. Hamdy, A. Hasan, K. Sirén, A multi-stage optimization method for cost-optimal nearly-zero-energy building solutions in line with the EPBD-recast 2010, Energy Build. 56 (2013) 189-203.

[21] L. Georges, C. Massart, G. Moeseke, A. De Herde, Environmental and economic performance of heating systems for energy-efficient dwellings: case of passive and low-energy single-family houses, Energy Policy 40 (1) (2012) 452-464.

[22] J. Kurnitski, A. Saari, T. Kalamees, M. Vuolle, J. Niemelä, T. Tark, Cost optimal and nearly zero (nZEB) energy performance calculations for residential buildings with REHVA definition for nZEB national implementation, Energy Build. 43 (11) (2011) 3279-3288.

[23] Marta J.N. Oliveira Panãoa, Miguel P. Rebeloa, Susana M.L. Cameloa, How low should be the energy required by a nearly zero-energy building? The load/generation energy balance of Mediterranean housing, Energy Build. 61 (2013) 161-171.

[24] European Standard EN 15459, Energy Performance of Buildings, Economic Evaluation Procedure for Energy Systems in Buildings, European Committee for Standardization, 2007

[25] F. Renard, S. Nourricier, M.D. Pietrantonio, V. Feldheim Technical-Economic Analysis of the Cost-Effectiveness of Energy Saving Investments for Residential Buildings. Technical Report, Service Public de Wallonie, DG04, Final Report, March (2008).

[27] D3 Finnish code of building regulation, Energy efficiency of buildings, Regulations and guidelines 2012, Helsinki, Finland (2011) (in Finnish).

[28] J. Kurnitski, A. Saari, T. Kalamees, M. Vuolle, J. Niemelä, T. Tark, Cost optimal and nearly zero (nZEB) energy performance calculations for residential buildings with REHVA definition for nZEB national implementation, Energy Build. 43 (11) (2011) 3279-3288.

[29] A.M. Papadopoulos, T.G. Theodosiou, K.D. Karatzas, Feasibility of energy saving renovation measures in urban buildings: the impact of energy prices and the acceptable payback time criterion, Energy Build. 34 (5) (2002) 455-466.

[30] M. Kantola, A. Saari, Renewable vs traditional energy management solutions e A Finnish hospital facility case, Renew. Energy 57 (2013) 539-545.

[31] Y. Bichioua, M. Krarti, Optimization of envelope and HVAC systems selection for residential buildings, Energy Build. 43 (2011) 3373-3382.

[32] S. Attia, M. Hamdy, S. Carlucci, L. Pagliano, S. Bucking, A. Hasan, Building performance optimization of net zero-energy buildings, in: A. Athienitis, W. O'Brien (Eds.), Modeling, Design, and Optimization of Net-Zero Energy Buildings, Wilhelm Ernst \& Sohn, Berlin, Germany, 2015, http://dx.doi.org/10. 1002/9783433604625.ch05.

[33] S. Attia, M. Hamdy, W. O'Brien, S. Carlucci, Assessing gaps and needs for integrating building performance optimization tools in net zero energy buildings design, Energy Build. 60 (5) (2013) 110-124.

[34] IEA. TASK 40/Annex 52. Towards net zero energy solar buildings, IEA SHC Task 40 and ECBCS Annex 52 (2008).

[35] AHSRAE Vision 2020, Providing tools by 2020 that enable the building community to produce market-viable NZEBs by 2030. ASHRAE Vision 2020 Ad Hoc Committee.

[36] AIA, The American Institute of Architects, 2030 Commitment. Measuring Industry Progress Toward 2030, The AIA, 1735 New York Avenue, NW, Washington, DC 20006, 2011, First Annual Report, available at http://www. aia.org/aiaucmp/groups/aia/documents/pdf/aiab089350.pdf.

[37] M. Hamdy, Combining Simulation and Optimisation for Dimensioning Optimal Building Envelopes and HVAC Systems, Aalto University Publication Series, 2012, Doctoral Dissertations 177/2012. ISBN 978-952-60-4937-3.

[38] M. Wetter, C. van Treeck, J. Hensen, New generation computational tools for building and community energy systems, in: IEA EBC Annex 60, 2015 http:// www.iea-annex60.org/downloads/Annex60Proposal.pdf.

[39] M. Al-Homoud, Computer-aided building energy analysis techniques, Build. Environ. 36 (2001) 421-433.

[40] P.D. Wilde, M.V.D. Voorden, Providing computational support for the selection of energy saving building components, Energy Build. 36 (2004) 749-758.

[41] C.J. Hopfe, C. Struck, G. Ulukavak Harputlugil, J. Hensen, P.D. Wilde, Exploration of using building performance simulation tools for conceptual building design, 20 October 2005 Delft, The Netherlands, in: IBPSA-NVL Conference, 8, 2005.

[42] S. Attia, M. Hamdy, M. Samaan, A. De Herde, J. Hensen, Towards strategic use of BPS tools in Egypt, in: Proceedings of the 12th International IBPSA Conference (BS2011), Sydney, Australia, 2011, pp. 40-47.

[43] C. Struck, Uncertainty Propagation and Parametric Analysis Techniques in Building Performance Simulation to Support Conceptual Building and System Design, 2012 https://www.bwk.tue.nl.

[44] IDA Early Stage Building Optimization (ESBO) by EQUA (2013) User Guide Version 1.09, $2013 \mathrm{http}$ ://www.equaonline.com/esbo/IDAESBOUserguide.pdf.

[45] B.A. Julstrom, Seeding the population: improved performance in a genetic algorithm for the rectilinear Steiner problem, in: A.Z. Phoenix (Ed.), Proceedings of the 1994 ACM Symposium on Applied Computing, New York: ACM Press, 1994, pp. 222-226.

[46] MATLAB (2013) Global Optimization Toolbox, Genetic Algorithm http://www. mathworks.nl/help/gads/ga.html? searchHighlight=ga.

[47] M. Hamdy, A. Hasan, K. Sirén, Combination of optimization algorithms for a multi-objective building design problem, in: IBPSA: 11th International Building Performance Simulation Association Conference, Glasgow-UK, 2009 http://www.ibpsa.org/proceedings/BS2009/BS09_0173_179.pdf.

[48] M. Hamdy, A. Hasan, K. Siren, Optimum design of a house and its HVAC systems using simulation-based optimization, Int. J. Low-Carbon Technol.s 5 (3) (2010) 120-124.
[49] M. Hamdy, A. Hasan, K. Siren, Impact of adaptive thermal comfort criteria on building energy use and cooling equipment size using a multi-objective optimization scheme, Energy Build. 43 (9) (2011) 2055-2067.

[50] R. Evins, Configuration of a genetic algorithm for multi-objective optimisation of solar gain to buildings, in: Proceedings of the Genetic and Evolutionary Computation Conference 2010, Portland OR. New York: ACM Press, 2010, pp. 2003-2006.

[51] R. Evins, P. Pointer, R. Vaidyanathan, Configuration of a genetic algorithm for multi-objective optimisation of solar gain to buildings, in: Proceedings of the genetic and evolutionary computation (GECCO)), GECCO 2010, New York, NY, USA : ACM, 2010, pp. 1327-1328, ACM ID: 1830726.

[52] G. Kayo, R. Ooka, Building energy system optimizations with utilization of waste heat from cogenerations by means of genetic algorithm, Energy Build. 42 (7) (2010) 985-991.

[53] J. Wright, A. Brownlee, M. Mourshed, Multi-objective optimization of cellular fenestration by an evolutionary algorithm, J. Build. Perform. Simul. (2013), http://dx.doi.org/10.1080/19401493.2012.762808 https://dspace.lboro.ac.uk/ dspace-jspui/bitstream/2134/11611/9/CellWinJnlPaper_ForRepository.pdf.

[54] MathWorks, online help: http://www.mathworks.nl/help/gads/populationdiversity.html? searchHighlight=initial\%20population\#btpz6n7 (1994-2014).

[56] N. Anh-Tuan, S. Reiter, P. Rigo, A review on simulation-based optimization methods applied to building performance analysis, Appl. Energy 113 (2014) 1043-1058, http://dx.doi.org/10.1016/j.apenergy.2013.08.061, ISSN 0306-2619.

[57] V. Machairas, A. Tsangrassoulis, K. Axarli, Algorithms for optimization of building design: a review, Renew. Sustain. Energy Rev. 31 (March) (2014) 101-112, http://dx.doi.org/10.1016/j.rser.2013.11.036, ISSN 1364-0321.

[58] M. Hamdy, M. Palonen, A. Hasan, Implementation of Pareto-Archive NSGA-II Algorithms to a Nearly-Zero-Energy Building Optimisation Problem, BSO12 IBPSA-England, 10-11 September, Loughborough University UK, 2001, 2012 $181-187$.

[59] EU, Guidelines accompanying commission delegated regulation (EU) No 244/2012 of 16 January 2012 supplementing Directive 2010/31/EU of the European Parliament and of the Council on the energy performance of buildings by establishing a comparative methodology framework for calculating cost-optimal levels of minimum energy performance requirements for buildings and building elements, Off. J. Eur. Union 2012 (2016).

[60] D5 National Building Code of Finland, Calculation of power and energy needs for heating of buildings, in: Guidelines 2012, Ministry of the Environment, Department of the Built Environment, 2010, DRAFT 28 September 2010.

[61] Ralph P. Evins, P. Pointer, Stuart C. Burgess, Multi-objective optimisation of a modular building for different climate types, in: Paper Presented at Proceedings: Building Simulation and Optimisation Conference, Loughborough, United Kingdom, 2012.

[62] Statistics Finland, available at http://www.stat.fi/hae en?q=Price+of+gas+by+Type+of+Consumer\&submit.

[63] Bank of Finland, Available at: http://www.suomenpankki.fi/en/tilastot/korot/ Pages/tilastot_markkina-_ja_hallinnolliset_korot_viitekorot_chrt_en.aspx.

[64] J. Jokisaloa, J. Kurnitski, M. Korpi, T. Kalamees, J. Vinha, Building leakage infiltration, and energy performance analyses for Finnish detached houses, Build. Environ. 44 (2009) 377-387.

[65] http://eartheasy.com/live_led_bulbs_comparison.html.

[66] B. Lapillonne, K. Pollier, Energy Efficiency Trends for Households in the EU. Enerdata, 2014 http://www.odyssee-mure.eu/publications/efficiency-bysector/household/household-eu.pdf.

[67] http://www.alibaba.com/showroom/mineral-wool-insulation-price-mineralwool.html.

[68] Fortum Company, Fortum.fi. 72, 1993. http://hansontank.us/ hotwaterbuffertanks.html (Accessed 30 May 2017)

[69] Fortum Company, Fortum.fi (Accessed 30 May 2017).

[70] http://en.wolf-heiztechnik.de/.

[71] Helsingin Energia, available at: http://helen.fi/index_eng.html.

[72] http://www.taloon.com/tuotteet/1293/dg.

[73] http://www.gebwell.fi/.

[75] C.A.J. Duijvestein, Ecologisch Bouwen, Faculty of Architecture, Deft the Netherlands: Delft University of Technology, 1993 (in Dutch).

[76] E. Lysen, The trias energica: solar energy strategies for developing countries, in: A. Goetzberger, J. Luther (Eds.), Proceedings of the EUROSUN Conference, 16-19 September, Freiburg, Germany: DGS Sonnenenergie Verlags-GmbH, 1996.

[77] T. Kalamees, K. Jylhä, H. Tietäväinen, J. Jokisalo, S. Ilomets, R. Hyvönen, S. Saku, Development of Weighting Factors for Climate Variables for Selecting the Energy Reference Year According to the EN ISO 15927-4 Standard, 2012.

[78] M. Hamdy, A. Nguyen, J. Hensen, A performance comparison of multi-objective optimization algorithms for solving nearly-zero-energy-building design problems, Energy Build. 121 (1) (2016) 57-71, ISSN 0378-7788.

[79] S.M. Attia Hamdy, W. O’Brien, S. Carluccie, Computational optimization for zero energy buildings design: interviews results with twenty eight international expert, in: 13th International Conference of the International Building Performance Simulation Association (BS2013), France, 2013. 